ARTICLE

https://doi.org/10.1038/s41467-019-11003-4

\title{
Adipocyte $\beta$-arrestin-2 is essential for maintaining whole body glucose and energy homeostasis
}

Sai P. Pydi ${ }^{1}$, Shanu Jain ${ }^{1}$, Wesley Tung ${ }^{1}$, Yinghong Cui ${ }^{1}$, Lu Zhu (1) 1, Wataru Sakamoto', Shalini Jain², Brent S. Abel ${ }^{3}$, Monica C. Skarulis ${ }^{3}$, Jie Liu ${ }^{4}$, Thanh Huynh ${ }^{5}$, Karel Pacak ${ }^{5}$, Marc G. Caron ${ }^{6}$, Oksana Gavrilova $^{2}$, Toren Finkel ${ }^{4} \&$ Jürgen Wess ${ }^{1}$

$\beta$-Arrestins are major regulators of $G$ protein-coupled receptor-mediated signaling processes. Their potential roles in regulating adipocyte function in vivo remain unexplored. Here we report the novel finding that mice lacking $\beta$-arrestin-2 (barr2) selectively in adipocytes show significantly reduced adiposity and striking metabolic improvements when consuming excess calories. We demonstrate that these beneficial metabolic effects are due to enhanced signaling through adipocyte $\beta 3$-adrenergic receptors ( $\beta 3$-ARs), indicating that barr 2 represents a potent negative regulator of adipocyte $\beta 3-A R$ activity in vivo. Interestingly, essentially all beneficial metabolic effects caused by adipocyte barr2 deficiency are absent in adipocyte barr2-PRDM16 double KO mice, indicating that the metabolic improvements caused by the lack of barr2 in adipocytes are mediated by the browning/beiging of white adipose tissue. Our data support the novel concept that ' $G$ protein-biased' $\beta 3$-AR agonists that do not promote $\beta 3-A R /$ barr 2 interactions may prove useful for the treatment of obesity and related metabolic disorders.

\footnotetext{
${ }^{1}$ Molecular Signaling Section, Laboratory of Bioorganic Chemistry, National Institute of Diabetes and Digestive and Kidney Diseases, Bethesda, MD NIH20892, USA. ${ }^{2}$ Mouse Metabolism Core, National Institute of Diabetes and Digestive and Kidney Diseases, Bethesda, MD 20892, USA. ${ }^{3}$ Diabetes, Endocrinology, and Obesity Branch, National Institute of Diabetes and Digestive and Kidney Diseases, Bethesda, MD 20892, USA. ${ }^{4}$ Center for Molecular Medicine, National Heart, Lung, and Blood Institute, Bethesda, MD 20892, USA. ${ }^{5}$ Section on Medical Neuroendocrinology, Eunice Kennedy Shriver National Institute of Child Health and Human Development, Bethesda, MD 20892, USA. ${ }^{6}$ Department of Cell Biology, Duke University Medical Center, Durham, NC 27710, USA. Correspondence and requests for materials should be addressed to J.W. (email: jurgenw@niddk.nih.gov)
} 
O besity represents a major risk factor for developing type 2 diabetes (T2D), cardiovascular disorders, immune dysfunction, various types of cancer, and several other severe human diseases ${ }^{1}$. The finding that adult humans harbor both classical brown adipose tissue (BAT) and brown-like or beige adipocytes in white adipose tissue (WAT) has generated immense interest in the obesity/metabolism field ${ }^{2-8}$. Brown/beige adipocytes utilize lipids and glucose as a fuel source and expend energy as heat, a process referred to as adaptive thermogenesis ${ }^{4,7}$. Importantly, the browning/beiging of WAT can counteract fat accumulation and improve whole body glucose homeostasis in experimental animals ${ }^{9-12}$. Taken together, these observations have stimulated intense efforts to develop novel anti-obesity drugs that are able to promote the browning/beiging of WAT depots ${ }^{11,13,14}$.

Adaptive thermogenesis function is predominantly mediated by UCP1 present in the inner mitochondrial membrane ${ }^{11,14,15}$. However, recent studies also implicate a creatine-driven substrate cycle in stimulating adaptive thermogenesis in beige adipocytes $^{16,17}$. Upon cold exposure or hormonal or chemical stimulation, beige adipocytes can emerge in WAT depots ${ }^{11,13,14,18}$. Thus, a better understanding of the cellular pathways that regulate the appearance of beige fat is likely to stimulate the development of novel therapies for the treatment of obesity and its associated metabolic disorders.

Adipocyte function, like that of virtually all other cell types, is regulated by the activity of cell surface $G$ protein-coupled receptors (GPCRs) ${ }^{19}$. For example, human subcutaneous fat expresses transcripts for more than 150 non-odorant GPCRs ${ }^{19}$. Importantly, activation of adipocyte $\beta$-adrenergic ${ }^{4,14}$ and $A_{2 a}$ adenosine receptors ${ }^{20}$, which primarily stimulate $G_{\mathrm{s}}$-mediated signaling, promotes the beiging of WAT and non-shivering thermogenesis.

The activity of most GPCRs is regulated by $\beta$-arrestin- 1 and- 2 (barr1 and barr2, respectively), two intracellular proteins that bind to activated GPCRs, thus terminating GPCR signaling and promoting receptor internalization ${ }^{21}$. However, $\beta$-arrestins can also act as signaling molecules in their own right ${ }^{22,23}$. Various lines of evidence indicate that $\beta$-arrestins play important roles in regulating many key metabolic functions ${ }^{24,25}$. However, the observed in vivo phenotypes are difficult to interpret since the two $\beta$-arrestins are expressed in most tissues and cell types.

In this study, we used adipocyte-specific mutant mouse models to examine the potential role of barr2 in regulating adipocyte function and whole body glucose homeostasis. Strikingly, mice selectively lacking barr2 in adipocytes are protected against high fat diet (HFD)-induced weight gain and the associated metabolic deficits.

Our new data showing that barr2 acts as a strong negative regulator of adipocyte $\beta 3$-adrenergic receptor ( $\beta 3$-AR) signaling should prove useful to design novel strategies to stimulate the browning/beiging of WAT for therapeutic purposes. For example, novel $\beta$-AR agonists that can activate $G$ proteins with high potency but are unable to interact with $\beta$-arrestins (so-called ' $G$ protein-biased' agonists) are predicted to promote beiging of WAT with considerably greater efficacy than non-biased $\beta$-AR agonists.

\section{Results}

Generation of adipocyte-selective barr2 knockout mice. To examine the physiological function of barr2 in adipose tissue, we inactivated barr2 selectively in adipocytes. Specifically, we crossed floxed barr 2 mice (barr $2 \mathrm{f} / \mathrm{f}$ mice $)^{26}$ with adipoq-Cre mice, which express Cre recombinase under the control of the adipocyte-specific adiponectin promoter ${ }^{27}$. Figure 1a shows that barr 2 mRNA expression levels were greatly reduced in epididymal fat (eWAT) and subcutaneous inguinal fat (iWAT) of barr $2 \mathrm{f} / \mathrm{f}$ mice carrying the adipoq-Cre transgene. In contrast, barr2 transcript levels were only slightly reduced in BAT (Fig. 1a), in agreement with previous observations that the use of adipoq-Cre mice ${ }^{27}$ often results in a more efficient deletion of floxed genes in WAT, as compared to BAT (see, for example ref. ${ }^{16}$ ). The expression of barr2 in other metabolically relevant tissues was not altered in adipoq-Cre barr $2 \mathrm{f} / \mathrm{f}$ mice, as compared to barr $2 \mathrm{f} / \mathrm{f}$ control animals (Fig. 1a).

We also studied barr2 expression levels using RNA prepared from purified primary mature adipocytes from three different fat pads (Fig. 1b). Adipocytes isolated from iWAT or eWAT from adipoq-Cre barr2 $\mathrm{f} / \mathrm{f}$ mice showed a pronounced reduction $(>80 \%)$ in barr2 expression (Fig. 1b). In contrast, adipocytes from BAT displayed only a $\sim 40 \%$ decrease in barr 2 transcript levels (Fig. 1b). The disruption of the barr2 gene in adipocytes had no significant effect on barrl expression levels in different fat depots or other metabolically relevant tissues (Supplementary Fig. 1a). Consistent with the mRNA expression data, Western blotting studies indicated that barr2 protein was no longer detectible in iWAT but was still highly expressed in BAT of adipoq-Cre barr $2 / f$ mice (Supplementary Fig. 2). For simplicity, we refer to the adipoq-Cre barr2 $\mathrm{f} / \mathrm{f}$ mice as 'adipo-barr2-KO mice' throughout this manuscript.

Adipo-barr2-KO mice show reduced adiposity and enhanced energy expenditure. When control and adipo-barr2-KO mice were raised on standard chow, no significant differences in body weight and body composition were observed between the two mouse lines (Supplementary Fig. 1b-d).

To investigate a potential role of adipocyte barr2 in the development of obesity, control and adipo-barr2-KO mice (males) were maintained on a HFD at room temperature $\left(23^{\circ} \mathrm{C}\right)$ for several weeks (HFD feeding was initiated when the mice were 4 weeks old). Under these conditions, adipo-barr2-KO mice gained considerably less weight than their control littermates (Fig. 1c). After 16 weeks of HFD feeding, the mutant mice weighed $\sim 15 \%$ less than the corresponding control mice (Fig. 1c, f). This decrease in body weight was associated with a significant reduction in fat mass in the barr2 mutant mice, as determined by magnetic resonance scanning (Fig. 1d, e). Lean body mass was not significantly different between the two groups (Fig. 1d).

We also measured energy expenditure, $\mathrm{O}_{2}$ consumption rate, food intake, and ambulatory activity in control and adipo-barr2$\mathrm{KO}$ mice after 8 weeks of HFD feeding $\left(23^{\circ} \mathrm{C}\right)$. Interestingly, adipo-barr2-KO mice showed significantly increased total energy expenditure (TEE) when TEE was normalized by body weight (Supplementary Fig. 3a). However, TEE was significantly reduced when TEE was expressed as TEE/mouse/day (Supplementary Fig. 3b). There were no significant differences in respiratory exchange ratio (RER; ratio of $\mathrm{CO}_{2}$ produced to $\mathrm{O}_{2}$ consumed), ambulatory activity, and food intake between the two groups (Supplementary Fig. 3c-f).

To test the hypothesis that increased TEE was the cause of the reduced fat mass displayed by the mutant mice under the HFD regime, we conducted indirect calorimetry measurements at the beginning of the HFD feeding period when the two groups of mice did not differ in body weight (Fig. 1g). Under these conditions, adipo-barr2-KO mice also showed significant increases in TEE (Fig. 1h) and $\mathrm{O}_{2}$ consumption (ml/mouse/h) (Fig. 1i). In contrast, RER, locomotor activity, and food intake remained similar in control and mutant mice (Fig. 1j-l). The increase in energy expenditure displayed by the adipo-barr2-KO mice consuming the HFD was not observed when mice were maintained on regular chow (Supplementary Fig. 4). 
a

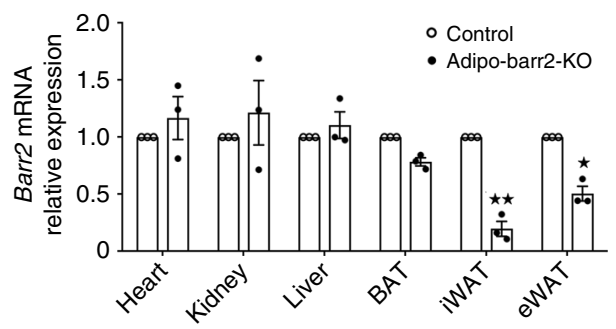

b

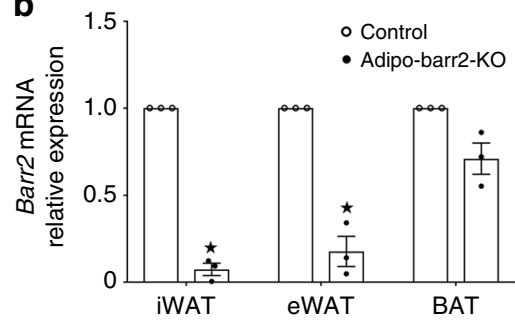

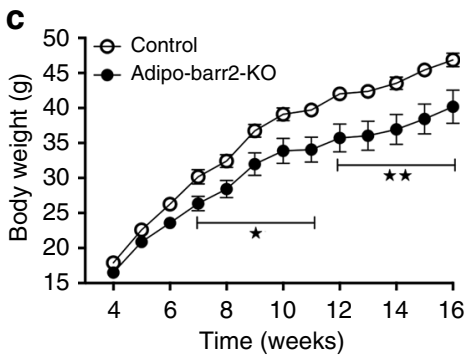

$\mathbf{d}_{35}$ - conorat
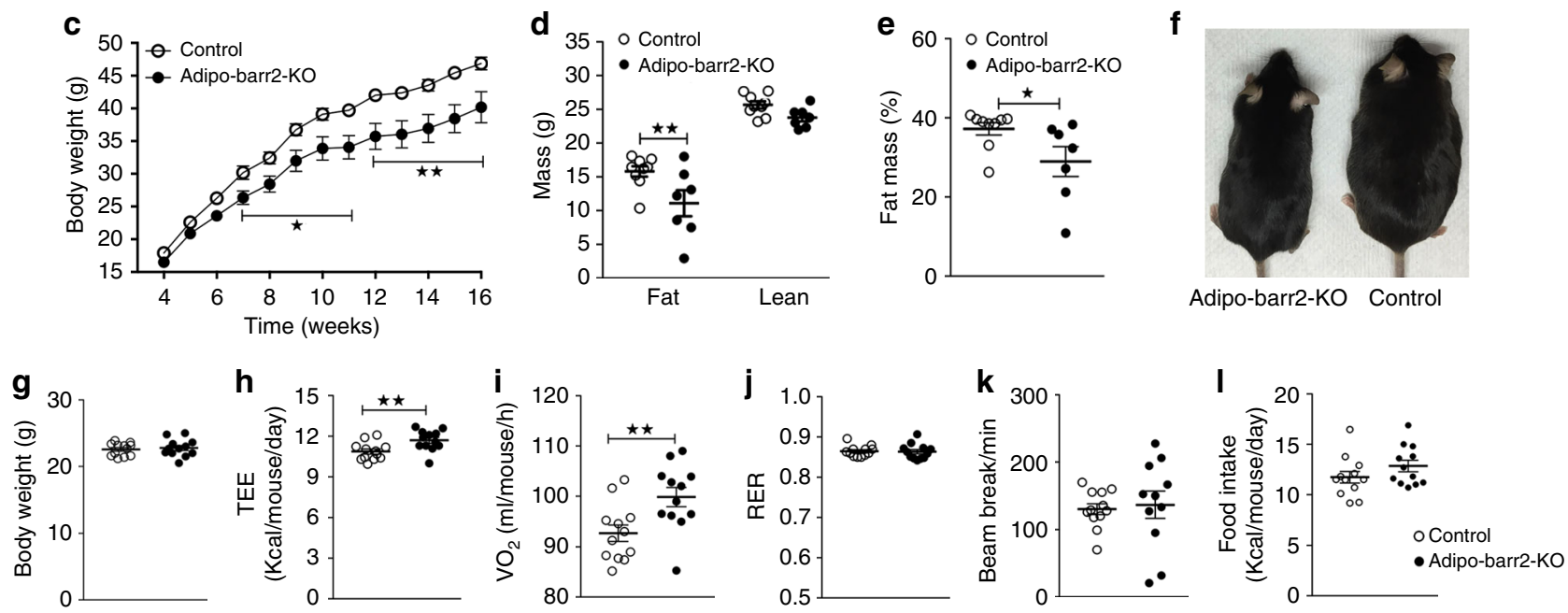

Fig. 1 Mice lacking barr2 in adipocytes show decreased body weight and fat mass, and increased energy expenditure when maintained on a HFD. a Expression of barr 2 mRNA in different tissues of adipo-Cre barr $2 / f$ mice and control littermates (barr $2 f / f$ ). Barr2 expression data are normalized relative to the expression of $\beta$-actin ( $n=3$ per group). For simplicity, we refer to the adipo-Cre barr2 $f / f$ mice as adipo-barr2-KO mice throughout the manuscript. $\mathbf{b}$ Relative mRNA expression levels of barr 2 in isolated mature adipocytes from iWAT, eWAT, and BAT ( $n=3$ or 4 per group). c Body weights of control and adipo-barr2-KO mice consuming a HFD ( $n=7-9$ per group). d, e Body composition (d) and fat mass (\% of body weight) (e) of mice maintained on a HFD for 12 weeks ( $n=7-9$ per group). f Images of representative control and adipo-barr2-KO KO mice (12-week-old males on HFD). g-k Metabolic studies during the initial phase of HFD feeding (first week; mouse age: 6-7 weeks). $\mathbf{g}$ Body weight. $\mathbf{h}$ Total energy expenditure (TEE). i Oxygen consumption rate $\left(V_{2}\right)$. j Respiratory exchange ratio (RER). k Ambulatory activity. I Food intake. Measurements were carried out using the Oxymax/CLAMS system ( $n=12$ male mice per group). All data are expressed as means \pm s.e.m. ${ }^{\star} p<0.05,{ }^{\star \star} p<0.01$ (a, b, d, e, g-I two-tailed Student's $t$-test; $\mathbf{c}$ two-way ANOVA followed by Bonferroni's post hoc test)

We also measured cumulative food intake of 8-9-week-old HFD mice over a period of 12 days (mice were housed individually and food intake was measured every 3 days). This analysis showed that cumulative food intake during this period was very similar in control and adipo-barr2-KO mice (control, $48.2 \pm 1.8$ g; KO, $49.7 \pm 1.9$ g; $n=12$ mice per group).

These data strongly suggest that increased energy expenditure causes the reduction in obesity displayed by the HFD mutant mice.

Adipo-barr2-KO mice are protected against obesity-induced metabolic deficits. We next subjected control and adipo-barr2$\mathrm{KO}$ mice to a series of in vivo metabolic tests. When mice were maintained on standard chow, we observed no significant differences in glucose and insulin tolerance tests between the two groups (Supplementary Fig. 5a, b). Moreover, fed and fasting blood glucose, fed plasma insulin, and plasma leptin levels were not affected by the barr 2 mutation (Supplementary Fig. $5 \mathrm{c}$-e). We only noted a small decrease in plasma insulin levels in fasted adipo-barr2-KO mice (Supplementary Fig. 5d).

A completely different pattern emerged when control and adipo-barr2-KO mice were maintained on a HFD for at least 8 weeks. Under these conditions, adipo-barr2-KO mice showed greatly improved glucose tolerance (Fig. 2a) and insulin sensitivity (Fig. 2b). Both fed and fasted barr2 mutant mice showed significantly reduced blood glucose levels, as compared to the corresponding control mice (Fig. 2c). At the same time, HFD adipo-barr2-KO mice displayed a pronounced reduction in plasma insulin levels under both fasting and fed conditions (Fig. 2d), consistent with the notion that the lack of WAT barr2 leads to enhanced insulin sensitivity. Taken together, these data indicate that adipo-barr2-KO mice are largely protected against the metabolic deficits associated with the consumption of a HFD.

We also measured plasma adipokine levels in HFD adipobarr2-KO mice and control littermates. Plasma leptin and resistin levels were significantly reduced in HFD adipo-barr2-KO mice (Fig. 2e, g), consistent with the observation that these mice showed reduced adiposity (see Fig. 1d, e). Somewhat surprisingly, plasma adiponectin levels were also significantly decreased in the barr2 mutant mice (under fasting conditions only) (Fig. 2f). Moreover, the plasma levels of several proinflammatory cytokines, including MCP-1, IFN- $\gamma$, TNF- $\alpha$, and IL6, were also significantly reduced in HFD adipo-barr2-KO mice (Fig. 2h-k).

Adipo-barr2-KO mice show enhanced iWAT beiging. To identify cellular pathways that are altered by the lack of barr2 in iWAT, we prepared iWAT RNA from adipo-barr2-KO and control mice maintained on HFD for 8 weeks. The RNA samples were then subjected to RNA-seq analysis. Overall, 2000 genes were upregulated and $\sim 550$ genes were downregulated in iWAT 

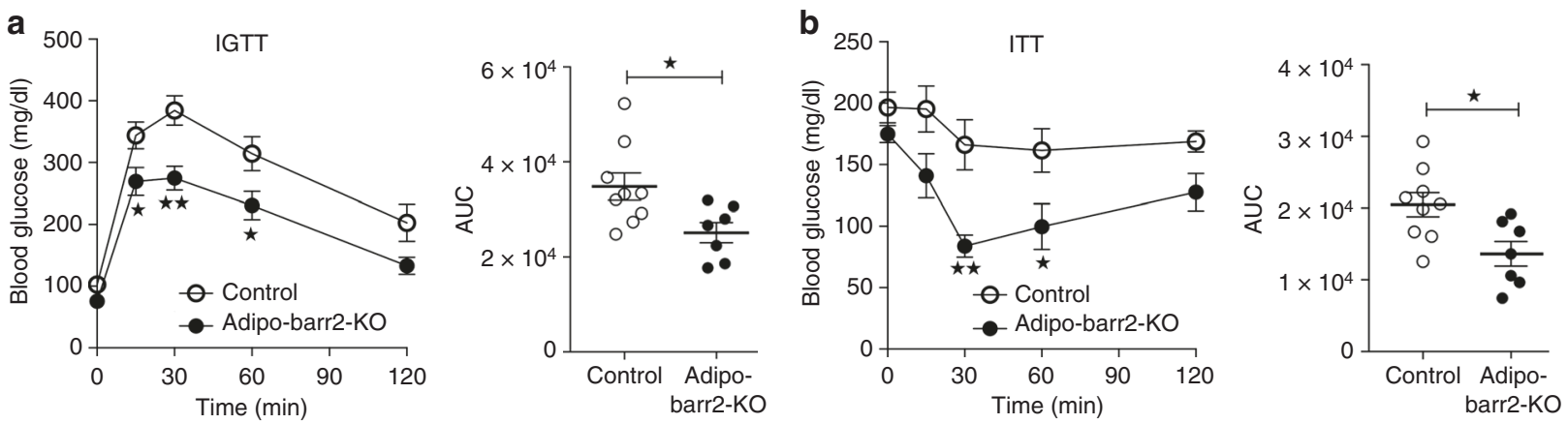

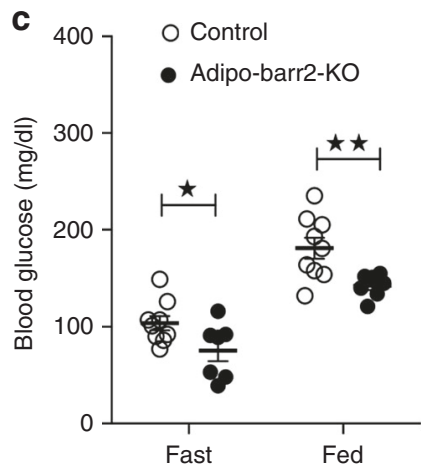

d

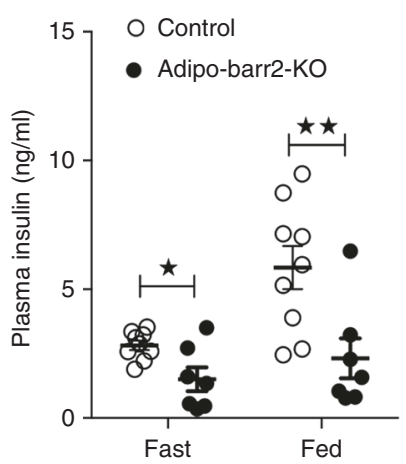

f

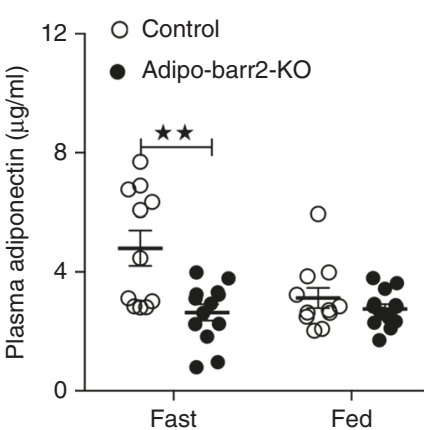

i

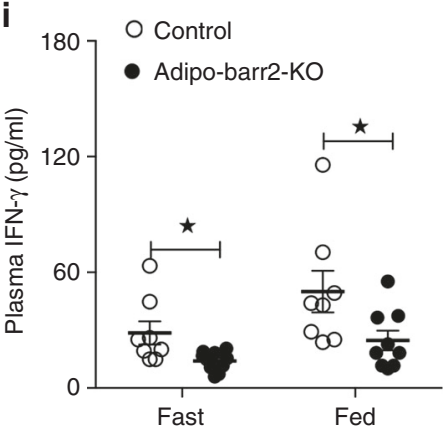

g

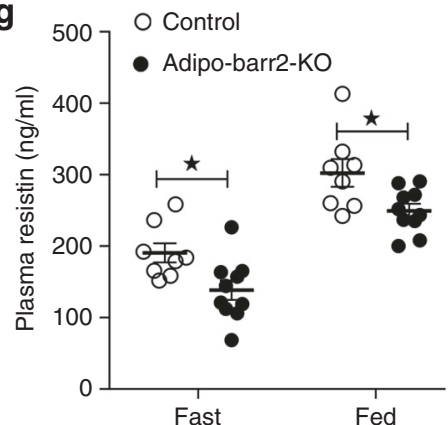

j

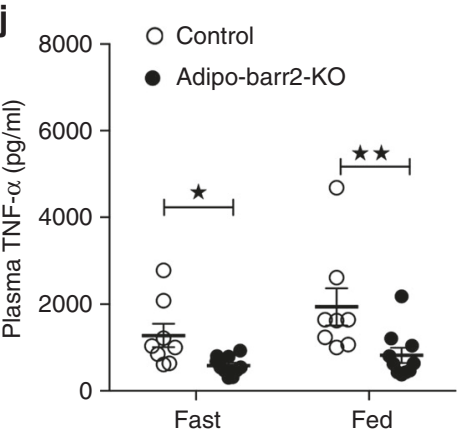

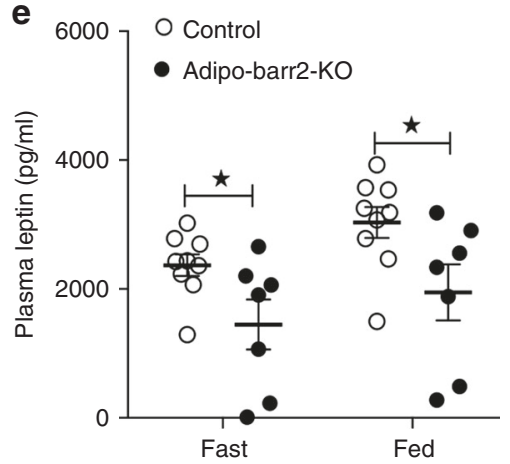

h

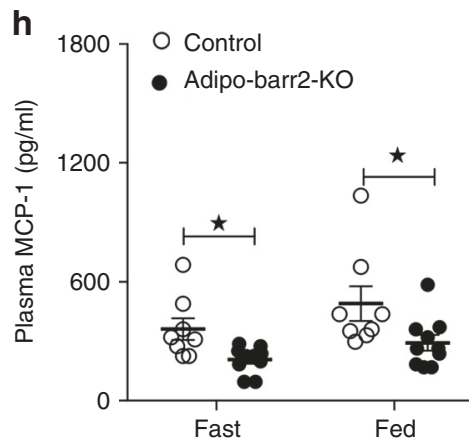

$\mathbf{k}$

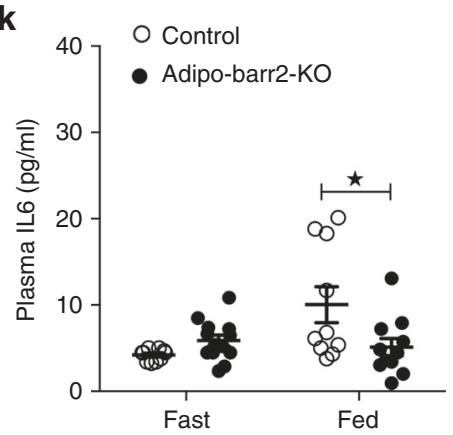

Fig. 2 Adipo-barr2-KO mice are protected against the detrimental metabolic effects caused by the consumption of a HFD. a, b In vivo metabolic tests. Control and adipo-barr2-KO mice maintained on HFD for 8-9 weeks were subjected to i.p. glucose tolerance (1 g glucose/kg; IGTT) (a) and insulin tolerance tests ( $1 \mathrm{U}$ insulin/kg i.p.; ITT) (b) ( $n=7-9 /$ group). AUC, area under the curve. c, d Freely fed and fasting blood glucose (c) and plasma insulin levels (d) of control and adipo-barr2-KO mice maintained on HFD for 8-9 weeks ( $n=7-9 /$ group). e-g Freely fed and fasting plasma leptin (e), adiponectin (f), and resistin ( $\mathbf{g}$ ) levels in control and adipo-barr2-KO mice maintained on HFD for 12 weeks ( $n=7-10 /$ group). h-k Plasma levels of proinflammatory cytokines. MCP-1 (h), IFN- $\gamma(\mathbf{i})$, TNF- $\alpha(\mathbf{j})$, and IL6 (k) plasma levels in control and adipo-barr2-KO mice fed with HFD for 12 weeks ( $n=8-11 /$ group). All experiments were carried out with male mice. Data are given as means \pm s.e.m. ${ }^{\star} p<0.05,{ }^{\star \star} p<0.01$ (a, $\mathbf{b}$ two-way ANOVA followed by Bonferroni's post hoc test or two-tailed Student's $t$-test (AUC); c-k two-tailed Student's $t$-test)

lacking barr2 (cutoff: $\log 2$ fold change $\geq 1.5$ (Supplementary Fig. 6a, b). Most strikingly, this analysis showed that the expression of many key marker genes indicative of iWAT beiging, including Ucp1, Cidea, Tmem26, CD137, Tbx1, Epsti1, Bmp7, and $C K m t 2$, was significantly increased in barr2-deficient iWAT
(Fig. 3a). We also observed significant changes in the expression levels of various mitochondrial adipocyte marker genes and of genes involved in lipid metabolism (Supplementary Fig. 6b). qRTPCR studies confirmed that barr2 deficiency in iWAT caused robust increases in the expression levels of genes critically 

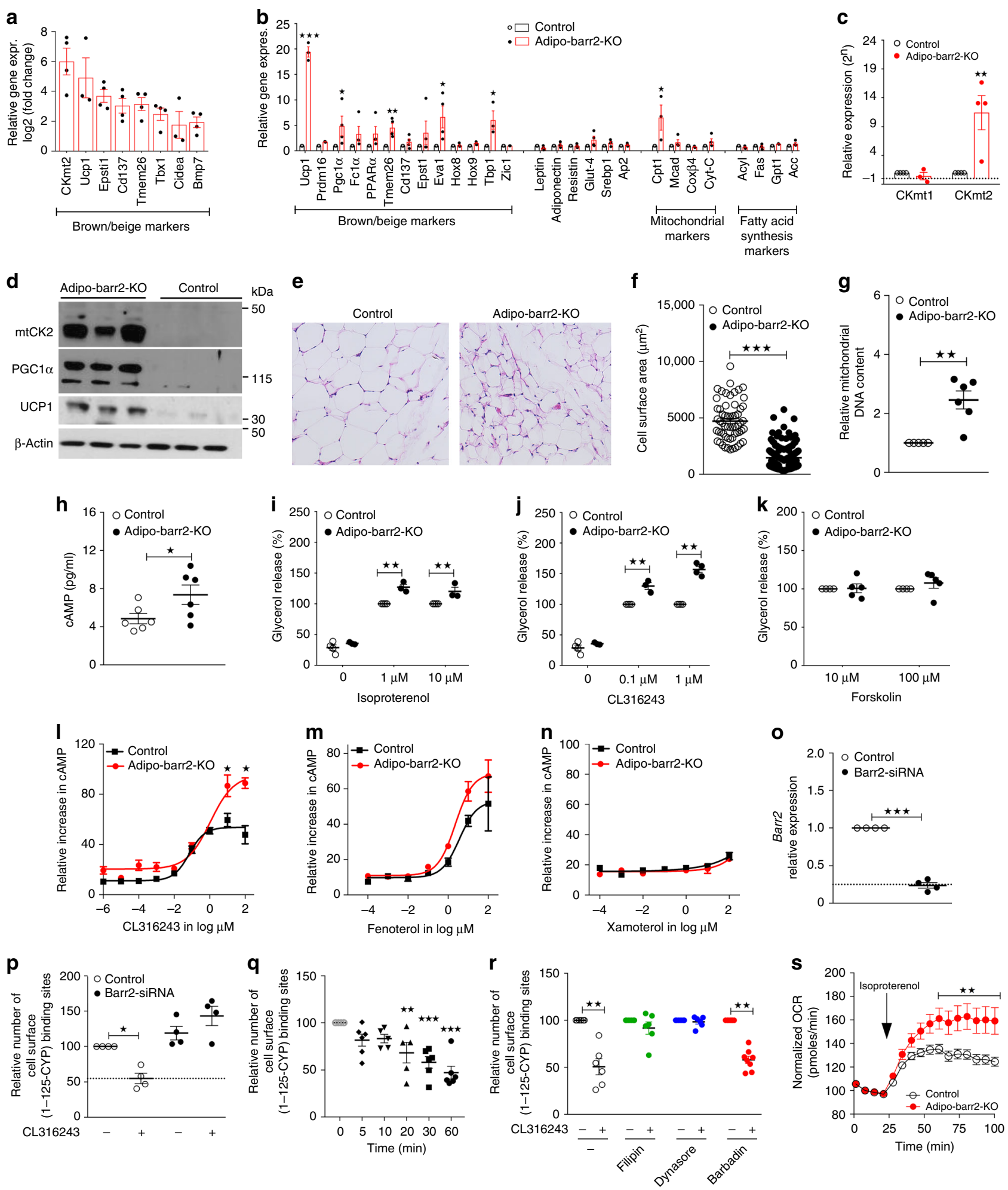

involved in iWAT browning/beiging (Fig. 3b, c). In contrast to iWAT, BAT isolated from HFD control and adipo-barr2-KO mutant mice did not show any significant changes in thermogenic marker genes (Supplementary Fig. 6c). In eWAT lacking barr2, the expression of only some browning/beiging-associated genes was elevated, including Tbx1 and CKmt2 (Supplementary Fig. 6d).

In agreement with the gene expression data, the protein expression levels of Ucp1, CKmt2, and Pgcla were dramatically increased in iWAT lysates prepared from HFD adipo-barr2-KO mutant mice (Fig. 3d). We also observed that creatine kinase activity was significantly enhanced in mitochondria from iWAT of adipo-barr2-KO mice, as compared to mitochondrial preparations from iWAT of control littermates (Supplementary Fig. 7).

H\&E staining experiments showed that adipocyte size was greatly reduced in iWAT lacking barr2 (Fig. 3e, f). While the beiging of IWAT in young, lean mice consuming regular chow leads to the appearance of multilocular adipocytes, this 
Fig. 3 Lack of barr2 promotes WAT browning/beiging and enhances signaling through adipocyte $\beta 3$-ARs. a Upregulation of genes promoting mouse iWAT browning/beiging in the absence of barr2 (RNA-seq analysis; HFD for 8 weeks; $n=3$ or 4 per group). b, $\mathbf{c}$ Enhanced expression of genes involved in iWAT browning/beiging in the absence of barr2 (qRT-PCR analysis; HFD for 8 weeks; $n=3$ or 4 per group). $\mathbf{d}$ Western blotting studies show striking increases in CKmt2, PGC-1 $\alpha$, and UCP1 protein levels in iWAT prepared from adipo-barr2-KO mice (HFD for 12 weeks). e Representative H\&E-stained iWAT sections from iWAT (HFD for 16 weeks). $\mathbf{f}$ Reduction in adipocyte size in iWAT from adipo-barr2-KO mice (HFD for 16 weeks; $n=3$ per group). $\mathbf{g}$ Mitochondrial DNA content (iWAT; HFD mice; $n=4$ or 5 per group). $\mathbf{h}$ Tissue cAMP concentrations in iWAT (HFD mice; $n=6$ per group). i-k Glycerol release studies. Mature adipocytes were stimulated with the indicated agents ( $n=3$ or 4 mice per group; diet: regular chow). I-n cAMP measurements. Mature adipocytes were incubated with $\beta$-AR subtype-selective agonists, followed by cAMP measurements: CL316243 ( $\beta 3$-selective; (I)), fenoterol ( $\beta 2$-selective; (m)), and xamoterol ( $\beta 1$-selective; $(\mathbf{n})$ ). Drug effects are expressed relative to cAMP responses caused by $100 \mu \mathrm{M}$ forskolin $(n=4$ or 5 mice per group; diet: regular chow). o Efficient reduction of barr2 mRNA expression after treatment of 3T3-F442A cells with barr2 siRNA ( $n=4$ per group). p Cell surface $\beta 3$-AR expression levels after 30 min treatment of 3T3-F442A cells with CL316243 $(1 \mu \mathrm{M})$. Prior to CL316243 incubation, cells had been treated with either barr2 siRNA or scrambled control RNA ( $n=4$ per group). q Time course of disappearance of cell surface $\beta 3$-ARs of 3T3-F442A cells stimulated with CL316243 $(1 \mu \mathrm{M})(n=3)$. $\mathbf{r}$ Incubation of 3T3-F442A cells with filipin $(1 \mu \mathrm{g} / \mathrm{ml})$ and dynasore $(80 \mu \mathrm{M})$, but not barbadin $(100 \mu \mathrm{M})$, prevents the loss of cell surface $\beta 3$-ARs triggered by CL316243 $(1 \mu \mathrm{M})$ treatment for $30 \mathrm{~min}(n=3)$. s Oxygen consumption rate (OCR) of differentiated adipocytes derived from iWAT of adipo-barr2-KO mice is significantly increased after isoproterenol $(10 \mu \mathrm{M})$ treatment. Normalized data are shown (basal levels $=100 \%)(n=3)$. Male mice were used for all studies. Data are given as means \pm s.e.m. ${ }^{\star} p<0.05,{ }^{\star \star} p<0.01,{ }^{\star \star \star} p<0.001$ (b, $\mathbf{c}, \mathbf{f}-\mathbf{q}$ two-tailed Student's $t$-test; $\mathbf{r}$ two-way ANOVA followed by Bonferroni's post hoc test)

morphological change is usually absent in iWAT undergoing beiging under a HFD regime (Patrick Seale, personal communication) (Fig. 3e).

To quantitate iWAT mitochondrial DNA content, we determined the ratio of mitochondrial to genomic DNA by real-time PCR (see Methods for details). As expected, this analysis revealed a significant increase in mitochondrial DNA levels in iWAT of HFD adipo-barr2-KO mice, as compared to HFD control mice (Fig. 3g).

In contrast to the findings obtained with iWAT from HFD adipo-barr2-KO mice, UCP1 and PGC1 $\alpha$ protein levels were similar in BAT from HFD adipo-barr2-KO and control animals (Supplementary Fig. 8a). Moreover, total BAT weight did not differ significantly between the two groups of mice (Supplementary Fig. 8b). We also treated mature adipocytes from adipo-barr2-KO and control mice groups with CL316243, a selective $\beta 3-\mathrm{AR}$ agonist known to enhance BAT activity by stimulating triglyceride breakdown in a cAMP-dependent fashion $^{28-30}$. Biochemical experiments showed that CL316243 stimulated lipolysis and increased intracellular cAMP levels to a similar extent in mutant and control BAT cells (Supplementary Fig. 8c, d). These observations are consistent with the finding that barr2 expression remained high in BAT from adipo-barr2-KO (Fig. 1a, b), suggesting that classical BAT does not play a critical role in causing the metabolic phenotypes displayed by the HFD adipo-barr2-KO mice.

Barr2 inhibits signaling through $\beta 3$-ARs in mouse iWAT. WAT and BAT are richly innervated by sympathetic nerves, and increased activity of the sympathetic nervous system (SNS) triggers lipolysis in WAT and thermogenesis in BAT or beige fat ${ }^{30}$. These SNS functions are mediated by activation of $\beta$-ARs which belong to the superfamily of biogenic amine GPCRs ${ }^{30}$. The $\beta$-AR family comprises three distinct members, $\beta 1, \beta 2$, and $\beta 3$. All three receptors are expressed by mouse adipocytes, although the $\beta 3-\mathrm{AR}$ represents the predominant $\beta$-AR receptor subtype in murine adipocytes $(\beta 3>\beta 2>\beta 1)^{30}$. Importantly, activation of $\beta$-ARs induces browning/beiging of WAT, a response that is most easily detectable in iWAT $11,13,14,28$.

Since barr2 is known to bind to activated $\beta$-ARs ${ }^{21}$, we hypothesized that the lack of barr 2 may lead to enhanced $\beta$-AR signaling in adipocytes of adipo-barr2-KO mice. To test this hypothesis, we first measured cAMP levels in iWAT from HFD adipo-barr2-KO and control mice (note that $\beta$-AR signaling stimulates adenylyl cyclase via activation of $G_{s}$ ). We found that cAMP levels were significantly elevated in iWAT lacking barr2
(Fig. 3h). Increased $\beta$-AR signaling in adipocytes also promotes lipolysis via cAMP-dependent pathways ${ }^{30}$. To examine whether $\beta$-AR-mediated lipolysis was altered in the absence of barr2, we stimulated mature, isolated adipocytes from iWAT of adipobarr2-KO and control mice with two different $\beta$-AR agonists, isoproterenol and CL316243. While isoproterenol is an agonist at all three $\beta$-AR subtypes, CL316243 selectively activates $\beta 3$-ARs ${ }^{29}$. We found that both agonists stimulated lipolysis to a significantly greater extent in iWAT-derived adipocytes lacking barr2 than in control adipocytes (Fig. 3i, j).

To exclude the possibility that barr2 interfered with lipolytic processes by modulating intracellular pathways in a receptorindependent fashion, we stimulated mature, iWAT-derived adipocytes with forskolin, a direct activator of adenylyl cyclase. We found that forskolin $(10$ and $100 \mu \mathrm{M})$ stimulated lipolysis to a similar extent in control and barr2-deficient adipocytes (Fig. 3k), supporting the concept that barr2 acts upstream of adenylyl cyclase, most likely at the $\beta$-AR level.

To identify the $\beta$-AR subtype responsible for the observed increase in cAMP production in barr2-deficient adipocytes, we treated mature, iWAT-derived mutant and control adipocytes with subtype-selective $\beta$-AR agonists ( $\beta 3$, CL316243; $\beta 2$, fenoterol; $\beta 1$, xamoterol), followed by the measurement of intracellular cAMP levels. The $\beta 3-A R$ agonist CL316243 showed significantly greater efficacy in barr2-deficient adipocytes, as compared to control adipocytes (Fig. 31). The $\beta 2-\mathrm{AR}$ selective agonist fenoterol stimulated cAMP production in a similar fashion in control and $\mathrm{KO}$ adipocytes (Fig. $3 \mathrm{~m}$ ), while xamoterol (selective agonist for $\beta 1$-ARs) was essentially devoid of functional activity in both groups of adipocytes (Fig. 3n).

Taken together, these data strongly suggest that barr2 deficiency selectively enhances signaling through $\beta 3$-ARs in mouse adipocytes (iWAT).

Barr2 mediates $\beta 3$-AR internalization in adipocytes. Previous studies with cultured cells demonstrated that activated $\beta 3$-ARs are unable to interact with $\beta$-arrestins ${ }^{31,32}$, providing a possible explanation for several reports that $\beta 3$-ARs do not undergo activity-dependent internalization or desensitization $31,33,34$. For this reason, the $\beta 3-\mathrm{AR}$ is generally considered an 'atypical' member of the GPCR superfamily $30,31,33,34$.

Given the fact that barr2 deletion in adipocytes greatly enhanced agonist-induced signaling through $\beta 3$-ARs (Fig. 31), we speculated that barr2 regulation of $\beta 3$-AR internalization might occur in adipocytes, in contrast to other cell types studied previously. To address this question, we carried out receptor 
internalization studies using mouse 3T3-F442A adipocytes that express almost exclusively the $\beta 3$-AR subtype ${ }^{35}$. After treatment of 3T3-F442A cells with either control siRNA or barr2 siRNA (Fig. 3o), we stimulated cells with CL316243 $(1 \mu \mathrm{M})$ at $37^{\circ} \mathrm{C}$ for 30 min. Subsequently, we selectively labeled cell surface $\beta 3$-ARs with $\left[\mathrm{I}^{125}\right]$-cyanopindolol ([I $\left.\left.{ }^{125}\right] \mathrm{CYP}, 1 \mathrm{nM}\right)$ at $4{ }^{\circ} \mathrm{C}$ (please note that CYP acts as a membrane-impermeable ligand at $4{ }^{\circ} \mathrm{C} ; 3^{36}$ see Methods for details). In control cells, CL316243 stimulation led to a pronounced loss (internalization) of $\sim 50 \%$ of cell surface $\beta 3$ ARs (Fig. 3p). In striking contrast, CL316243-induced $\beta 3$-AR internalization was completely abolished in 3T3-F442A cells following barr2 knockdown (Fig. 3p). A time course of the disappearance of cell surface $\beta 3$-ARs of CL316243 (1 $\mu \mathrm{M})$-treated 3T3-F442A cells is shown in Fig. 3q. Interestingly, CL316243induced $\beta 3-\mathrm{AR}$ internalization remained unaffected by treatment of 3T3-F442A cells with barbadin $(100 \mu \mathrm{M})$, a small molecule that selectively inhibits $\beta$-arrestin-mediated GPCR endocytosis via clathrin-coated pits ${ }^{37}$ (Fig. 3r). On the other hand, $\beta 3-A R$ sequestration was completely prevented by incubation of cells with filipin $(1 \mu \mathrm{g} / \mathrm{ml})$ or dynasore $(80 \mu \mathrm{M})$ (Fig. $3 \mathrm{r})$. Dynasore is an inhibitor of dynamin that interferes with both clathrindependent and -independent endocytic pathways ${ }^{38}$. In contrast, filipin is a cholesterol-binding agent that is able to prevent caveolae/lipid raft-mediated GPCR endocytosis, a process that is also dynamin-dependent ${ }^{39}$. Taken together, our findings suggest that the activated $\beta 3$-ARs are internalized via a caveolae/lipid raft-dependent pathway in fat cells.

Using the same experimental strategy, we also studied agonistinduced $\beta 3$-AR internalization in HEK $293 \mathrm{~T}$ transiently expressing the mouse $\beta 3-\mathrm{AR}$. In contrast to our findings with 3T3F442A mouse adipocytes, treatment of $\beta 3$-AR-expressing HEK $293 \mathrm{~T}$ cells with CL316243 $\left(1 \mu \mathrm{M} ; 37^{\circ} \mathrm{C}\right.$ for $\left.30 \mathrm{~min}\right)$ failed to induce $\beta 3-A R$ internalization (Supplementary Fig. 9a). For control purposes, we demonstrated that isoproterenol $(10 \mu \mathrm{M})$ stimulation of HEK $293 \mathrm{~T}$ cells transiently expressing the human $\beta 2-\mathrm{AR}$ resulted in robust $\beta 2$-AR internalization (Supplementary Fig. 9b). These data support the novel concept that barr2 regulation of $\beta 3-\mathrm{AR}$ internalization is indeed cell-type-specific.

We also studied whether the absence of barr2 affected $\beta 3-A R$ expression levels in native mouse fat tissue. Specifically, we used conditions that allowed us to selectively label $\beta 3$-ARs in plasma membranes prepared from iWAT of adipo-barr2-KO and control mice (radioligand: $\left[\mathrm{I}^{125}\right] \mathrm{CYP}, 1 \mathrm{nM}$ ). Although there was a trend towards increased $\beta 3$-AR expression levels in barr2-deficient preparations, this difference failed to reach statistical significance $(p=0.37)$ (control: $22 \pm 4 \mathrm{fmol} / \mathrm{mg}, n=11$; adipo-barr2-KO: 32 $\pm 10, n=9$; means \pm s.e.m.).

Norepinephrine release is unchanged in adipo-barr2-KO mice. We next wanted to exclude the possibility that sympathetic tone is enhanced in adipo-barr2-KO mice, thus triggering enhanced $\beta 3$-AR signaling in adipocytes. To address this issue, we measured norepinephrine (NE) levels in iWAT and urine from adipo-barr2$\mathrm{KO}$ mice and control littermates. We found that iWAT and $24 \mathrm{~h}$ urine NE levels did not differ significantly between the two groups (Supplementary Fig. 10).

We also measured noradrenergic turnover in iWAT of HFD adipo-barr2-KO mice and control littermates by using a previously published method ${ }^{40}$. Specifically, the sums of the concentrations of NE, dopamine, DOPA (3,4-dihydroxyphenylalanine, an NE precursor), and DHPG (3,4-dihydroxyphenylglycol, an NE metabolite) were calculated and used as an index of noradrenergic turnover ${ }^{40}$. This analysis showed that the NE turnover index was very similar in iWAT of HFD adipo-barr2$\mathrm{KO}$ and control mice $(\mathrm{KO}, 48.4 \pm 3.2 \mathrm{ng} / \mu \mathrm{g}$ tissue; control, $48.0 \pm$
$5.7 \mathrm{ng} / \mu \mathrm{g}$ tissue; six male mice per group). These results indicate that the lack of barr2 had no significant effect on NE release/ turnover in iWAT of HFD adipo-barr2-KO mice.

$\beta$-AR activation promotes $\mathrm{O}_{2}$ consumption in barr2-deficient adipocytes. In adipocytes, increased adrenergic signaling is known to increase mitochondrial $\mathrm{O}_{2}$ consumption ${ }^{41,42}$. Consistent with the data shown in Fig. $3 \mathrm{~h}-\mathrm{j}$, isoproterenol $(10 \mu \mathrm{M}$ at $\left.37^{\circ} \mathrm{C}\right)$ and CL316243 $\left(1 \mu \mathrm{M}\right.$ at $\left.37^{\circ} \mathrm{C}\right)$ treatment of differentiated adipocytes derived from iWAT of adipo-barr2-KO mice caused a significant increase in mitochondrial $\mathrm{O}_{2}$ consumption rate (OCR), as compared to control cells (Fig. $3 \mathrm{~s}$ and Supplementary Fig. 11, respectively).

Analysis of HFD adipo-barr2-KO mice kept at thermoneutrality. At typical housing conditions $\left(22-24^{\circ} \mathrm{C}\right.$; 'room temperature'), mice show considerable sympathetic nervous system (SNS) activity in order to maintain their body temperature ${ }^{43}$. In contrast, SNS activity is relatively low at thermoneutrality $\left(30^{\circ} \mathrm{C}\right)^{43}$. We found that HFD adipo-barr2-KO mice and control littermates showed similar body weight gain when raised at $30^{\circ} \mathrm{C}$ (Fig. $4 \mathrm{a}, \mathrm{b}$ ). Similarly, no significant differences in lean or fat body mass (Fig. 4c), glucose tolerance (Fig. 4d), whole body insulin sensitivity (Fig. 4e), blood glucose and plasma insulin levels (Fig. 4f, g), oxygen consumption rate (Fig. 4h), and ambulatory activity (Fig. 4i) were observed between the mutant and control mice. Moreover, the pronounced increase in the expression of marker genes indicative of iWAT browning/beiging (Ucp1, Prdm16, CKmt2, and etc.) observed at room temperature with HFD adipo-barr2-KO mice was absent when mice were housed at thermoneutrality (Fig. 4j). These data are in agreement with the notion that the beneficial metabolic phenotypes displayed by HFD adipo-barr2-KO mice are dependent on the activity of the SNS (enhanced $\beta 3$-AR signaling in adipocytes).

Analysis of propranolol-treated HFD adipo-barr2-KO mice. We also placed 4-week-old adipo-barr2-KO mice and control littermates on a HFD for 8 weeks in the presence of propranolol, an antagonist of all $\beta$-AR subtypes (propranolol was added to the drinking water at a concentration of $0.5 \mathrm{~g} / \mathrm{kg}$ ) (Fig. 5a). In parallel, another set of $\mathrm{KO}$ and control mice was subjected to the same experimental protocol except that the drinking water lacked propranolol. When HFD adipo-barr2-KO mice and control mice were treated with propranolol, the two groups did not show any significant differences in body weight gain (Fig. 5b), lean or fat body mass (Fig. 5d), glucose tolerance (Fig. 5e), insulin sensitivity (Fig. 5g), blood glucose or plasma insulin levels (Fig. 5i, j), and expression levels of iWAT thermogenic marker genes (Fig. 5k). As expected, when HFD adipo-barr2-KO and control mice were not exposed to propranolol, the mutant animals showed significantly reduced body weight gain (Fig. 5c), reduced fat mass (Fig. 5d), improved glucose tolerance (Fig. 5f), enhanced insulin sensitivity (Fig. 5h), and reduced blood glucose or plasma insulin levels (Fig. 5i, j). These data clearly indicated that the beneficial metabolic changes displayed by HFD adipo-barr2-KO mice at room temperature required intact $\beta-\mathrm{AR}$ signaling.

Analysis of HFD adipo-barr2-PRDM16 double KO mice. PRDM16 is a transcriptional regulatory protein that is required for the conversion of white to beige fat ${ }^{7,11,14}$. For example, recent studies have shown that adipocyte-specific deletion of PRDM16 prevents the browning/beiging of $\mathrm{WAT}^{12}$. To study whether the metabolic phenotypes displayed by HFD adipobarr2-KO mice required the beiging of WAT, we generated adipocyte-specific barr2-PRDM16 double KO mice (adipoq-Cre $\operatorname{Prdm} 16 \mathrm{f} / \mathrm{f}$ barr2 $\mathrm{f} / \mathrm{f}$ mice). While HFD adipo-barr2 single KO 

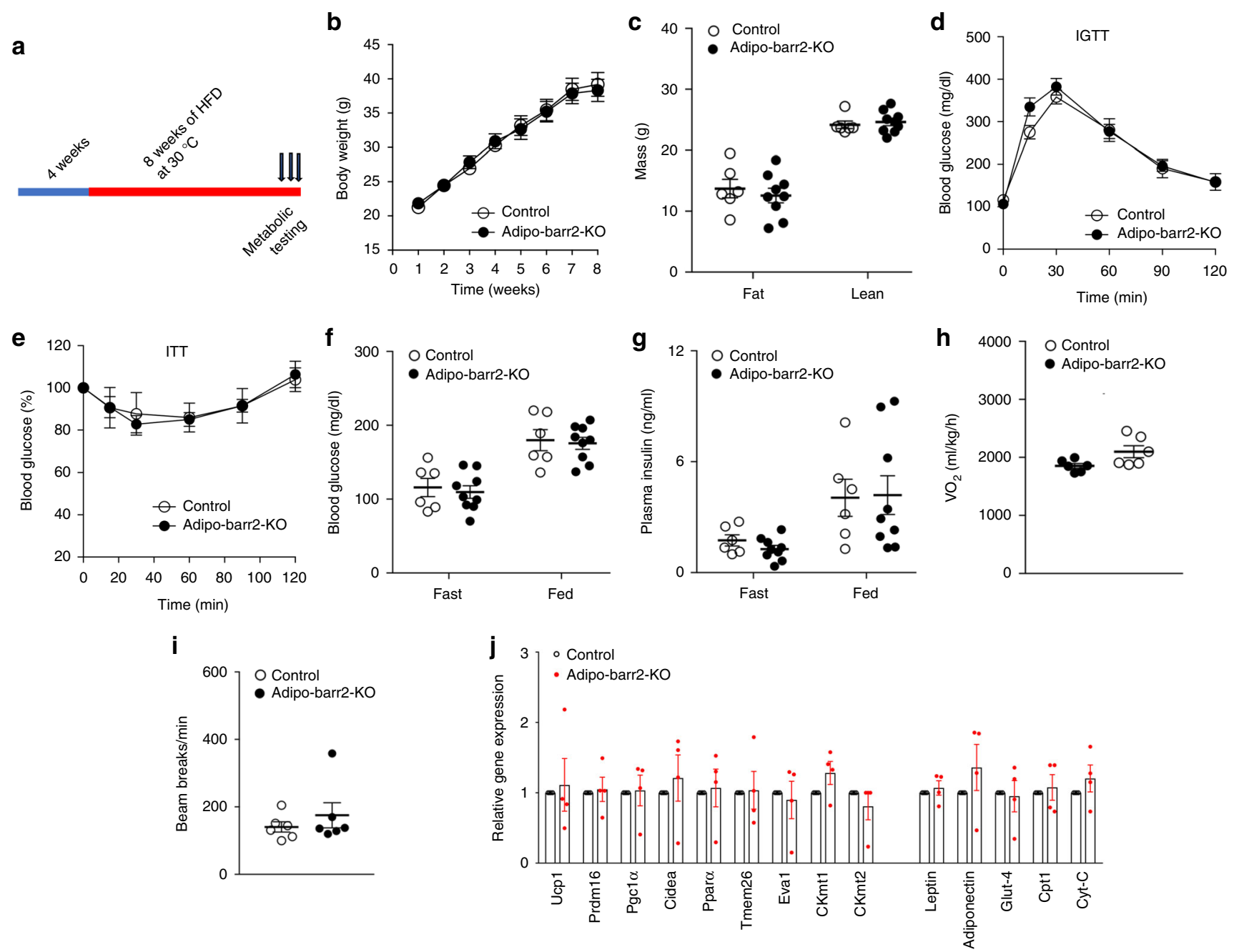

Fig. 4 HFD Adipo-barr2-KO mice show no metabolic changes at thermoneutrality. a Experimental time line. When control and adipo-barr2-KO mice reached 4 weeks of age, they were maintained on a HFD at thermoneutrality $\left(30^{\circ} \mathrm{C}\right)$. $\mathbf{b}$ Body weights of control and adipo-barr2-KO mice maintained on HFD at thermoneutrality ( $n=6-9$ per group). c Body composition of mice fed with HFD for 8 weeks at thermoneutrality ( $n=6-9$ per group). d I.p. glucose tolerance test ( $1 \mathrm{~g}$ glucose/ $\mathrm{kg}$; IGTT) carried out after 7-8 weeks of HFD feeding at thermoneutrality ( $n=6-9$ per group). e Insulin tolerance test ( $1 \mathrm{U}$ insulin/kg i.p.; ITT) performed after 7-8 weeks of HFD feeding at thermoneutrality ( $n=6-9$ per group). $\mathbf{f}, \mathbf{g}$ Freely fed and fasting blood glucose (f) and plasma insulin ( $\mathbf{g}$ ) levels measured after 7-8 weeks of HFD feeding at thermoneutrality ( $n=6-9$ per group). $\mathbf{h}, \mathbf{i} \mathrm{O}_{2}$ consumption rate (h) and ambulatory activity (i) at thermoneutrality after 7-8 weeks of HFD feeding ( $n=6-9$ per group). $\mathbf{j}$ Relative transcript levels of browning/beiging marker genes and other key metabolic genes determined by qRT-PCR analysis of iWAT RNA after 7-8 weeks of HFD feeding at thermoneutrality ( $n=4$ per group). All data are expressed as means \pm s.e.m. Male mice were used for all the experiments

mice showed a significant reduction in body weight (Fig. 1c, f), the HFD double KO mice exhibited a slight increase in body weight, as compared to the corresponding HFD control group ( Prdm $16 \mathrm{f} / \mathrm{f}$ barr $2 \mathrm{f} / \mathrm{f}$ mice) (Fig. 6a). A similar increase in body weight was observed with adipocyte-specific PRDM16 single $\mathrm{KO}$ mice ${ }^{12}$. This increase in body weight was associated with a significant increase in body fat mass (Fig. 6b; note that HFD adipo-barr2-KO mice showed a decrease in body fat mass). Moreover, the improvements in glucose tolerance and insulin sensitivity observed with HFD adipo-barr2-KO mice (Fig. 2a, b) were absent in HFD adipo-barr2-PRDM16 double KO mice (Fig. 6d, e). In addition, while HFD adipo-barr2-KO mice showed reduced blood glucose and plasma insulin levels (Fig. 2c, d), this effect was no longer observed in the HFD double $\mathrm{KO}$ mice (Fig. $6 \mathrm{f}, \mathrm{g}$ ). As expected due to the lack of PRDM16, the expression of several key thermogenic maker genes was drastically reduced in iWAT of HFD adipo-barr2PRDM16 double KO mice (Fig. 6h).
Taken together, these data strongly suggest that the beneficial metabolic phenotypes displayed by the HFD adipo-barr2-KO mice require the beiging of WAT.

BARR2 expression is human subcutaneous fat. We also examined whether $B A R R 2$ expression was altered in subcutaneous fat of obese subjects suffering from insulin resistance (for patient data, see Supplementary Table 1). Interestingly, qRT-PCR studies showed that BARR2 transcript levels were significantly increased in subcutaneous adipose tissue isolated from obese individuals, as compared to the corresponding BARR 2 mRNA levels obtained with samples from age-, race-, and sex-matched individuals who did not suffer from obesity and insulin resistance (Supplementary Fig. 12). These data suggest the possibility that increased BARR2 activity reduces $\beta$-AR signaling in adipose tissue of obese subjects, thus contributing to the pathophysiological changes associated with increased adiposity. 
a
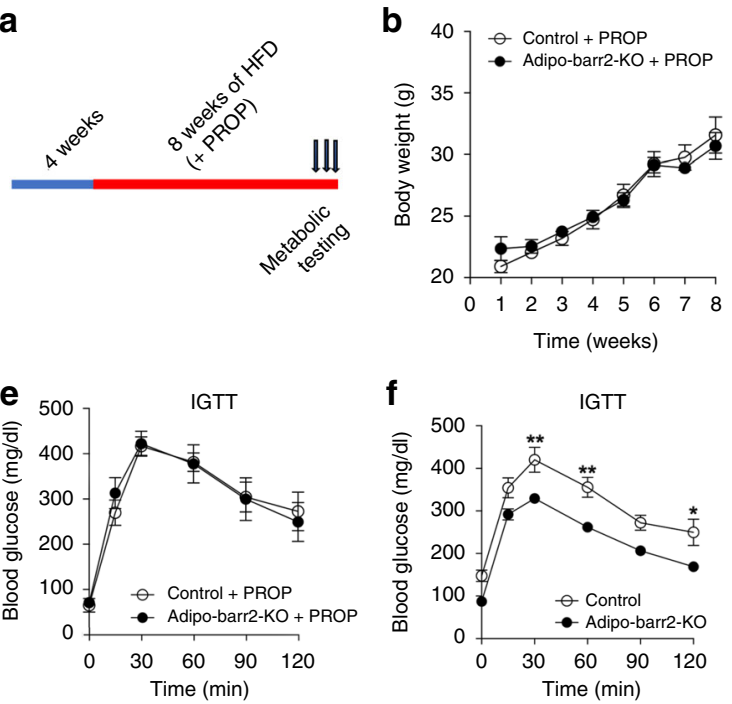

i

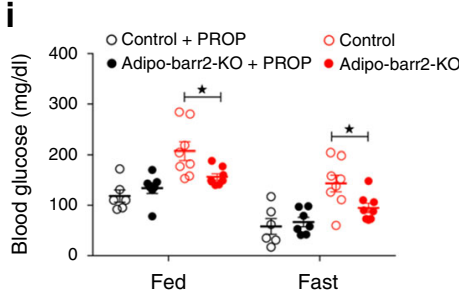

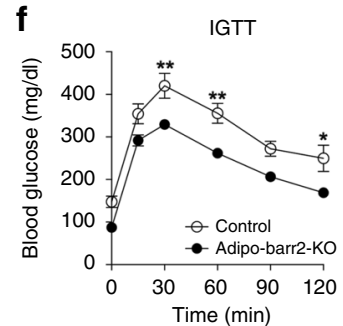

g

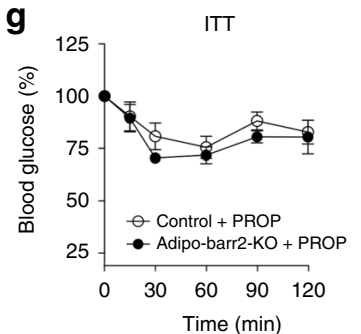

d
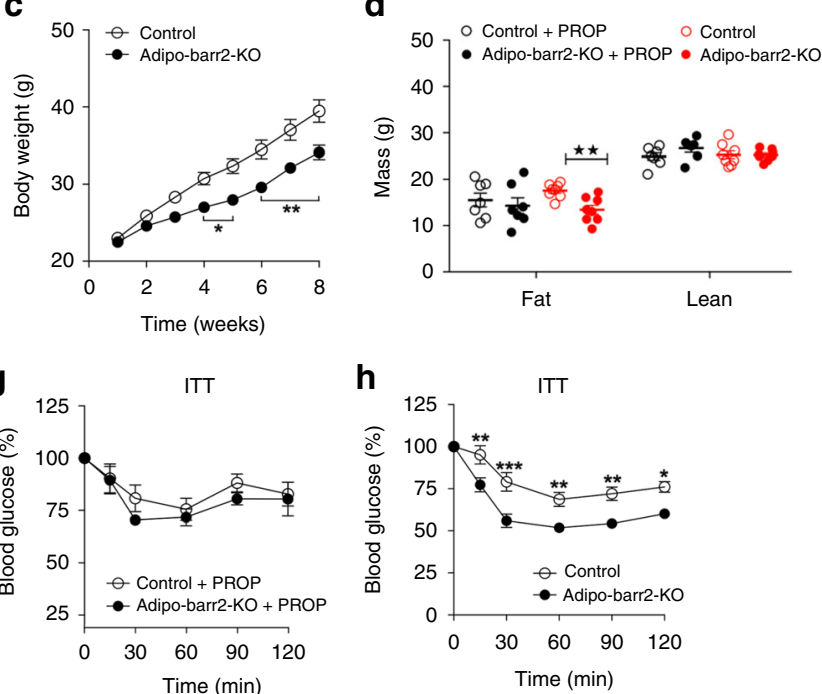
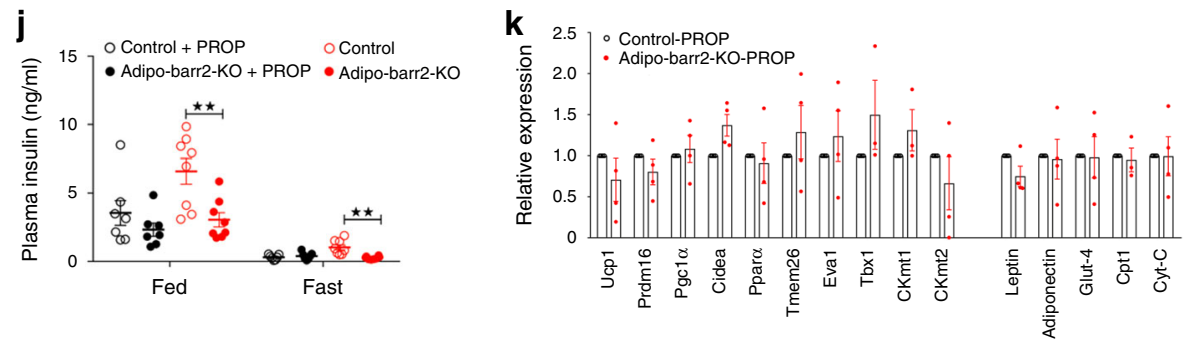

Fig. 5 In the presence of propranolol, HFD adipo-barr2-KO mice show no metabolic phenotypes. a Study design. When control and adipo-barr2-KO mice were 4 weeks old, they were maintained on a HFD at room temperature $\left(23^{\circ} \mathrm{C}\right)$ for at least 8 weeks. During HFD feeding, a subgroup of mice received drinking water containing propranolol (PROP) at $0.5 \mathrm{~g} / \mathrm{l}$. b, c Body weights during HFD feeding. In b, the drinking water was supplemented with PROP. In c, the mice received regular drinking water for control purposes $(n=6-8$ /group). d Body composition of mice consuming HFD for 10 weeks with or without PROP treatment ( $n=6-8$ /group). e, f I.p. glucose tolerance test ( $1 \mathrm{~g}$ glucose $/ \mathrm{kg}$; IGTT) in PROP-treated (e) or untreated (f) mice after 8 weeks of HFD feeding ( $n=6-8$ /group). $\mathbf{g}$, h I.p. insulin tolerance test ( $0.75 \mathrm{U}$ insulin/kg i.p.; ITT) in PROP-treated (g) or untreated (h) mice after 9 weeks of HFD feeding $(n=6-8 /$ group). $\mathbf{i}, \mathbf{j}$ Freely fed and fasting blood glucose (i) and plasma insulin (j) levels in PROP-treated or untreated mice after 8-9 weeks of HFD feeding ( $n=6-8$ /group). $\mathbf{k}$ Relative transcript levels of browning/beiging marker genes and other key metabolic genes determined by qRT-PCR analysis of iWAT RNA after 12 weeks of HFD feeding of PROP-treated mice ( $n=4$ per group). Male mice were used for all studies. Date are shown as means \pm s.e.m. ${ }^{\star} p<0.05,{ }^{\star \star} p<0.01,{ }^{\star \star \star} p<0.001$ (b, $\mathbf{c}, \mathbf{e}-\mathbf{h}$ two-way ANOVA followed by Bonferroni's post hoc test.; $\mathbf{d}, \mathbf{i}, \mathbf{j}$ two-tailed Student's $t$-test)

\section{Discussion}

In the present study, we demonstrated that adipocyte-specific barr2 KO mice displayed pronounced metabolic improvements when maintained on a HFD. These effects included reduced body weight gain and body fat mass, decreased blood glucose levels, and increases in glucose and insulin tolerance (Figs. 1,2). We also showed that these metabolic improvements were associated with the beiging of white fat (Fig. 3d, e), a pronounced upregulation of many browning/beiging-associated marker genes in white fat (iWAT) (Fig. 3a-c), and an increase in energy expenditure (Fig. 1h, i). Food intake was unaltered in HFD adipo-barr2-KO mice (Fig. 11). It is likely that the observed improvements in blood glucose homeostasis and insulin sensitivity are secondary to the decrease in adiposity displayed by the HFD adipo-barr2-KO mice. Consistent with this notion, the plasma levels of several proinflammatory adipokines were significantly reduced in HFD adipo-barr2-KO mice (Fig. 2h-k).

Recent work has shown that adipocyte-specific deletion of PRDM16 prevents the browning/beiging of $\mathrm{WAT}^{12}$. To test the hypothesis that the beneficial metabolic phenotypes displayed by HFD adipo-barr2-KO mice required the beiging of WAT, we generated and analyzed adipo-barr2-PRDM16 double KO mice. We found that essentially all beneficial metabolic effects caused by adipocyte barr 2 deficiency, including decreased body fat mass and increased glucose and insulin tolerance, were no longer observed with HFD adipo-barr2-PRDM16 double KO mice (Fig. 6). This observation strongly supports the concept that the metabolic improvements exhibited by HFD adipo-barr2-KO mice require the browning/beiging of WAT.

Activation of the SNS (e.g., by cold exposure) efficiently promotes the browning/beiging of $\mathrm{WAT}^{11,13,14}$. To test the potential involvement of the SNS in the metabolic changes characteristic for HFD adipo-barr2-KO mice, we housed the mutant mice, along with their control littermates, at thermoneutrality $\left(30^{\circ} \mathrm{C}\right)$. At thermoneutrality, the activity of the SNS is significantly reduced, as compared to room temperature ${ }^{43}$. Strikingly, the beneficial metabolic phenotypes displayed by HFD adipo-barr2 $\mathrm{KO}$ mice were no longer detectable at thermoneutrality (Fig. 4), providing additional evidence that the improved metabolic status caused by the lack of barr2 in adipocytes is dependent on the activity of the SNS.

Activation of the SNS leads to the release of NE from sympathetic nerve endings which affects adipocyte function by activating $\beta$-ARs ${ }^{30}$. To demonstrate the potential involvement of $\beta$ ARs in the observed metabolic changes, we treated HFD adipobarr2 $\mathrm{KO}$ mice and their control littermates with propranolol, an antagonist of all three $\beta$-ARs. Strikingly, propranolol treatment abolished all beneficial metabolic effects caused by the barr2 

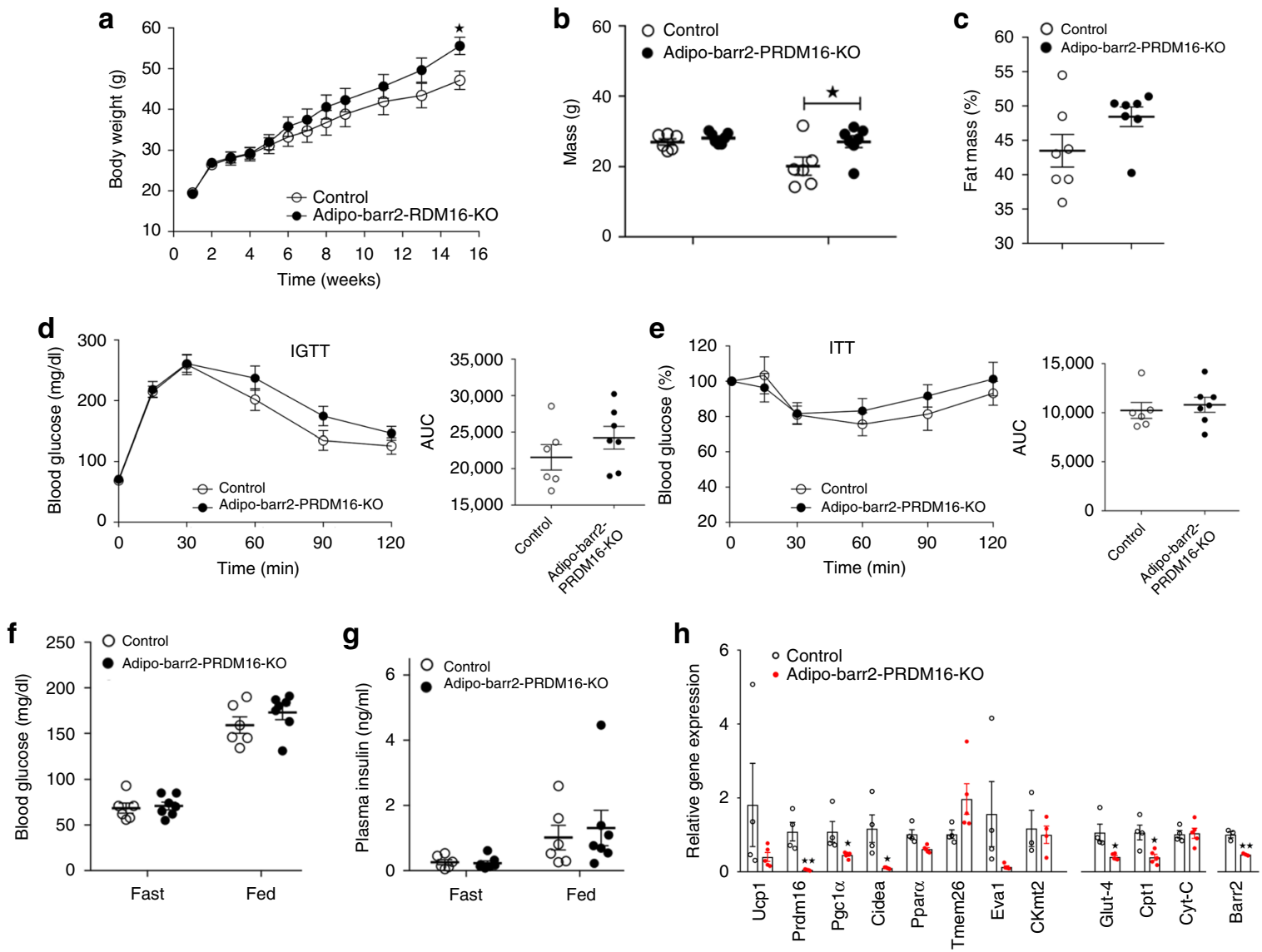

Fig. 6 The beneficial metabolic effects displayed by adipo-barr2-KO mice are absent in barr2-PRDM16 double KO mice. a Body weights of control mice (genotype: barr $2 f / f \operatorname{Prdm} 16 f / f$ ) and adipo-barr2-PRDM16 double KO mice (genotype: adipoq-Cre barr2 $f / f \operatorname{Prdm} 16 \mathrm{f} / \mathrm{f}$ ) maintained on a HFD after 4 weeks of age ( $n=6$ or 7 per group). b, c Body composition (b) and fat mass (\% of body weight) (c) of the indicated mouse strains maintained on a HFD for 15 weeks. d, e IGTT ( $1 \mathrm{~g}$ glucose $/ \mathrm{kg}$ i.p) (d) and ITT ( $0.75 \mathrm{U}$ insulin $/ \mathrm{kg}$ i.p.) (e). Mice were maintained on a HFD for $8-9$ weeks $(n=6$ or 7 per group). AUC, area under the curve. $\mathbf{f}, \mathbf{g}$ Freely fed and fasting blood glucose (f) and plasma insulin levels ( $\mathbf{g}$ ) in mice maintained on a HFD for 10 weeks ( $n=6$ or 7 per group). $\mathbf{h}$ Relative transcript levels of browning/beiging marker genes and other key metabolic genes, including barr2, determined by qRT-PCR analysis of iWAT RNA after 16 weeks of HFD feeding ( $n=4$ per group). Male mice were used for all studies. Data are expressed as means \pm s.e.m. ${ }^{\star} p<0.05,{ }^{\star \star} p<$ 0.01 (a two-way ANOVA followed by Bonferroni's post hoc test; $\mathbf{b}, \mathbf{c}, \mathbf{f}-\mathbf{h}$ two-tailed Student's t-test)

mutation (Fig. 5), clearly indicating that $\beta$-AR activity is essential for the phenotypic changes displayed by HFD adipo-barr2 $\mathrm{KO}$ mice.

All three $\beta$-ARs are expressed by mouse adipocytes, although the $\beta 3$-AR represents the predominant $\beta$-AR receptor subtype $(\beta 3>\beta 2>\beta 1)^{30}$. Functional assays with subtype-selective $\beta$-AR agonists demonstrated that barr2 deficiency selectively enhanced signaling through $\beta 3-\mathrm{AR}$ (Fig. 31-n).

Recent work by the Spiegelman group identified a UCP1independent thermogenic pathway that involves the stimulation of adipocyte creatine metabolism, promoting ATP production and consumption in mitochondria from beige fat ${ }^{16,17}$. It is likely that this pathway plays a key role in mediating the beneficial metabolic phenotypes exhibited by HFD adipo-barr2 KO mice. First, CKmt2 RNA and CKmt2 protein levels were dramatically increased in iWAT from HFD adipo-barr2 $\mathrm{KO}$ mice (CKmt2 is a key enzyme of a futile creatine cycle that is operative in beige fat) ${ }^{17}$ (Fig. $3 c, d$ ). Second, CK activity was greatly increased in mitochondria prepared from barr2-deficient iWAT, as compared to control preparations (Supplementary Fig. 7).

As discussed above, we convincingly demonstrated that barr2 acts as a potent inhibitor of $\beta 3$-AR signaling in adipocytes. Given previous findings that $\beta 3$-AR agonists can prevent or even reverse obesity and diabetes in various animal models ${ }^{13,30,44}$, our new observations are of particular interest.
Studies with various cell lines demonstrated that the $\beta 3$-AR, in contrast to the other two $\beta$-AR subtypes and most other GPCRs, is resistant to short-term, agonist-promoted internalization $^{31,33,34}$, most likely due to the lack of intracellular phosphorylation sites required for the recruitment of $\beta$ arrestins $^{34}$. Consistent with this observation, agonist-activated $\beta 3$-ARs failed to interact with $\beta$-arrestins, as studied via BRET or other experimental strategies ${ }^{31,32}$.

In the present study, we report the unexpected finding that selective stimulation of the $\beta 3$-AR expressed by cultured mouse adipocytes led to a rapid and robust internalization of $\beta 3$-ARs (Fig. 3p, q). Moreover, agonist-induced $\beta 3$-AR internalization was abolished following siRNA-mediated knockdown of barr2 in these cells (Fig. 3p), indicating that $\beta 3-A R$ internalization was mediated by barr2. These observations clearly demonstrate that $\beta 3-A R$ internalization is cell-type-specific. We speculate that barr2-mediated $\beta 3$-AR internalization requires additional cofactors that are only expressed in certain cell types such as adipocytes. Clearly, this topic remains to be studied in greater detail in future studies.

It should be mentioned in this context that several mutant GPCRs engineered to lack intracellular phosphorylation sites retained the ability to interact with $\beta$-arrestins in an agonistdependent fashion. Such GPCRs include, for example, the protease-activated receptor- $1^{45}$, the leutropin receptor ${ }^{46}$, and the 
leukotriene B4 receptor $1^{47}$. These observations further support the concept that agonist-induced GPCR phosphorylation is not an absolute requirement for $\beta$-arrestin recruitment.

Many studies have shown that structurally different agonists can stabilize different GPCR conformations, which differ in their ability to activate $\mathrm{G}$ proteins and/or to bind $\beta$-arrestins ${ }^{48-50}$. This finding has greatly stimulated the search for novel, so-called 'biased' agonists that lead to the preferential activation of $\mathrm{G}$ proteins or the selective recruitment of $\beta$-arrestins, respectively. As discussed in detail elsewhere, certain functionally biased agonists may become clinically useful drugs endowed with increased therapeutic efficacy and an improved side effect profile ${ }^{49-52}$. For example, several studies suggest that $G$ proteinbiased $\mu$-opioid receptor agonists may be able to relieve pain without causing the characteristic side effects (tolerance, addiction, etc.) associated with the use of morphine and other nonbiased $\mu$-receptor agonists (for a recent review, see ref. ${ }^{52}$ ). In a similar fashion, the development of $G$ protein-biased $\beta 3-A R$ agonists that do not trigger barr2-mediated $\beta 3$-AR internalization may lead to highly efficacious, novel therapeutic agents for the treatment of obesity and type 2 diabetes.

Whereas the $\beta 3$-AR is the predominant $\beta$-AR receptor subtype in rodent adipocytes, human fat cells preferentially express $\beta 1$ and $\beta 2$-ARs ${ }^{53}$. However, $\beta 3$-ARs are also expressed at significant (though lower) levels in human adipocytes ${ }^{53,54}$. In 2012, a selective $\beta 3$-AR agonist, mirabegron, has been approved for the treatment of overactive bladder, due to the presence of $\beta 3$-ARs on bladder smooth muscle cells. A recent proof-of-concept study demonstrated that acute treatment of healthy male individuals with a relatively high dose of mirabegron increased resting metabolic rate, and that this beneficial metabolic effect was associated with BAT activation ${ }^{55}$. However, earlier work had demonstrated that chronic treatment of human subjects with selective $\beta 3$-AR agonists did not lead to a sustained increase in energy expenditure or body weight reduction ${ }^{56,57}$, perhaps due to barr2-mediated loss of cell surface $\beta 3$-ARs. For this reason, the development of novel G protein-biased $\beta 3-\mathrm{AR}$ agonists that do not promote barr2 recruitment may provide important new tools to chronically stimulate energy expenditure for therapeutic purposes (see previous paragraph).

In conclusion, we showed, for the first time, that barr2 is a critical regulator of adipocyte function and whole body glucose and energy homeostasis. Our findings suggest that $G$ proteinbiased $\beta 3$-AR agonists may become clinically useful as novel therapeutic agents for the treatment of obesity and related metabolic disorders.

\section{Methods}

Drugs, reagents, commercial kits, and antibodies. All drugs, reagents, commercial kits, and antibodies and their sources are listed in Supplementary Table 2.

Animals. Mice lacking $\beta$-arrestin-2 (barr2; official gene name: arrb2) selectively in adipocytes were generated as described in the following. Floxed barr2 mice (barr2 $\mathrm{f} / \mathrm{f}$ mice) were obtained on a pure C57BL/6 J background ${ }^{26}$. Adipoq-Cre mice were purchased from the Jackson Laboratories (Stock No. 010803; genetic background: C57BL/6 J). Adipoq-Cre mice were crossed with barr2 $\mathrm{f} / \mathrm{f}$ mice to generate barr $2 \mathrm{f} / \mathrm{f}$ mice hemizygous for the adipoq-Cre transgene and barr $2 / f$ control mice. All mice were maintained on a pure C57BL/6 J background.

Adipocyte-specific Prdm16-barr2 double KO mice were generated by crossing adipoq-Cre barr $\mathrm{f} / \mathrm{f}$ mice with floxed $\operatorname{Prdm} 16$ mice (Prdm $16 \mathrm{f} / \mathrm{f}$ mice; these mice were kindly provided by Drs. Paul Cohen and Bruce Spiegelman ${ }^{12}$ ).

All animal studies were carried out according to the US National Institutes of Health Guidelines for Animal Research and were approved by the NIDDK Institutional Animal Care and Use Committee. We complied with all relevant ethical regulations for animal testing and research.

Mouse maintenance and diet. All experiments were carried out with male littermates. Unless stated otherwise, mice were maintained at room temperature $\left(23^{\circ} \mathrm{C}\right)$ on a standard chow (7022 NIH-07 diet, 15\% kcal fat, energy density $3.1 \mathrm{kcal} / \mathrm{g}$,
Envigo Inc.). The mice had free access to water and food, and were kept on a $12-\mathrm{h}$ light, 12-h dark cycle. In a subset of experiments, 4-5-week-old male mice were switched to a high fat diet (HFD; F3282, 50\% kcal fat, energy density $5.5 \mathrm{kcal} / \mathrm{gm}$, Bioserv). Mice consumed the HFD for at least 8 weeks, unless stated otherwise.

Gene expression analysis using qRT-PCR. Mouse tissues were collected and frozen quickly on dry ice. Total RNA was extracted and purified using the RNeasy mini kit (Qiagen). cDNA was synthesized using SuperScript ${ }^{\text {tx }}$ III First-Strand Synthesis SuperMix (Invitrogen), and quantitative PCR was performed using the SYBR green method (Applied Biosystems). RNA expression data were normalized relative to the expression of $\beta$-actin (Atcb) or $18 \mathrm{~S}$ rRNA using the $\Delta \Delta \mathrm{Ct}$ method. A complete list of primer sequences is provided in Supplementary Table 3.

Western blotting. Frozen tissues were homogenized in adipocyte lysis buffer (50 $\mathrm{mM}$ Tris, $\mathrm{pH} 7.4,500 \mathrm{mM} \mathrm{NaCl}, 1 \% \mathrm{NP} 40,20 \%$ glycerol, $5 \mathrm{mM}$ EDTA, and $1 \mathrm{mM}$ phenylmethylsulphonyl fluoride (PMSF)), supplemented with complete EDTA-free protease inhibitor cocktail (Roche). Cell lysates were centrifuged twice at 12,000 $\times g$ for $15 \mathrm{~min}^{17}$. Subsequently, the supernatants were aliquoted and stored at $-80^{\circ} \mathrm{C}$ for further analysis. Protein concentrations were determined by using a bicinchoninic acid assay kit (Pierce). Protein lysates were denatured at $95^{\circ} \mathrm{C}$ using NuPAGE LDS sample buffer (Thermo Fisher Scientific), and proteins were separated via SDS-PAGE followed by transfer to nitrocellulose membranes. Membranes were incubated overnight at $4^{\circ} \mathrm{C}$ with primary antibody, followed by treatment with an HRP-conjugated anti-rabbit or anti-goat secondary antibody. Specific protein bands were visualized by using SuperSignal West Pico Chemiluminescent Substrate (Pierce). Uncropped and unprocessed scans of the most important blots are shown in Supplementary Figs. 13 and 14

In vivo metabolic tests. In vivo metabolic tests were performed with adult male mice that were at least 8 weeks old. Glucose tolerance tests (IGTT) were carried out using mice that had been fasted overnight for $12 \mathrm{~h}$. Mice received 1 or $2 \mathrm{~g} / \mathrm{kg}$ (as indicated) of glucose i.p., and blood was collected from the tail vein at specific time points $(0,15,30,50,90$, and 120 min post-injection). Blood glucose concentrations were determined using a portable glucometer (Contour Glucometer; Bayer). For insulin tolerance tests, mice were fasted for 5-6 $\mathrm{h}$ and then injected i.p. with human insulin ( 0.75 or $1 \mathrm{U} / \mathrm{kg}$; Humulin, Eli Lilly). Subsequently, blood glucose levels were determined at time points similar to those used for the IGTT assay.

Determination of plasma insulin and leptin levels. Blood was collected from the tail vein of fasted mice ( $12 \mathrm{~h}$ overnight fast) or from mice that had free access to food using blood collection tubes. Plasma was obtained by centrifuging blood samples at $4{ }^{\circ} \mathrm{C}$ for $10 \mathrm{~min}$ at $\sim 12,000 \times \mathrm{g}$. Plasma insulin concentrations were measured using an ELISA kit (Crystal Chem Inc.) by following the manufacturer's instructions. Plasma leptin levels were measured using an ELISA kit (R\&D Systems).

Measurement of plasma adipokine and cytokine levels. Blood was collected from the mandibular/jugular vein with $\mathrm{K}_{2}$-EDTA-containing tubes (Microvette, Sarstedt) and then quickly centrifuged at $4{ }^{\circ} \mathrm{C}$ to collect plasma (see previous paragraph). Plasma adipokine and cytokine levels were measured using the BioPlex Multiplex Immunoassay System (Bio-Rad), following the manufacturer's instructions. The Luminex Milliplex Analyzer (Luminex) was used to determine adipokine/cytokine concentrations, as described by the manufacturer.

Differentiation of 3T3-F442A cells. 3T3-F442A preadipocytes (Kerafast) were maintained in DMEM supplemented with $10 \%$ bovine calf serum (BCS) in a $10 \%$ $\mathrm{CO}_{2}$ incubator at $37^{\circ} \mathrm{C}$. Two days after the cells had reached confluence, they were differentiated via incubation in DMEM containing $10 \%$ BCS, insulin $(0.5 \mu \mathrm{g} / \mathrm{ml})$, IBMX $(250 \mu \mathrm{M})$, TZD $(2 \mu \mathrm{M}$ rosiglitazone), dexamethasone $(0.5 \mu \mathrm{M})$, and indomethacin $(60 \mu \mathrm{M})$ for $48 \mathrm{~h}$. Subsequently, the cells were incubated with DMEM plus $10 \%$ BCS and insulin $(0.5 \mu \mathrm{M})$ for two days and then maintained in DMEM containing $10 \%$ BCS

Treatment of 3T3-F442A cells with barr2 siRNA. Barr2 siRNA pool (SMARTpool) and scrambled control siRNA were purchased from GE Dharmacon. On day 0, 3T3-F442A cells were transfected with siRNA using Lipofectamine RNAiMAX (Thermo Fisher Scientific) by following the manufacturer's instructions. Four hour later, cells were changed to differentiation media (see previous paragraph). On day 5, differentiated 3T3-F442A adipocytes were used for further experiments.

Generation of differentiated white adipocytes. Subcutaneous inguinal fat (iWAT) from 8-12-week-old mice (males) was digested at $37^{\circ} \mathrm{C}$ for $30-45 \mathrm{~min}$ in Krebs-Ringer-Hepes-bicarbonate buffer (KRH buffer) containing collagenase 1 (Sigma-Aldrich). The digested tissue suspension was filtered through a $100 \mu \mathrm{m}$ cell strainer, followed by centrifugation at $400 \times g$ for $5 \mathrm{~min}$ at room temperature. The cell pellet was resuspended in Dulbecco's PBS (dPBS) and filtered through a $40 \mu \mathrm{m}$ 
cell strainer. The cell suspension was centrifuged again as above to obtain a pellet containing the stromal vascular fraction (SVF). The pellet was resuspended in DMEM containing $10 \%$ FBS, supplemented with pen-strep and glutamine $(200 \mu \mathrm{M})$. Cells were initially plated in 6-well plates. After having reached $50 \%$ confluency, cells were re-plated in Seashore XF 96 well plates at a density of 6000 cells/well. Once the cells had reached confluency, they were differentiated into white adipocytes using differentiation media containing insulin, IBMX, TZD, dexamethasone, and indomethacin (for details, see previous paragraph). After $48 \mathrm{~h}$, media were replaced with DMEM containing 10\% FBS and $0.5 \mu \mathrm{M}$ insulin. About $24 \mathrm{~h}$ before experiments, media were replaced with DMEM supplemented with $10 \% \mathrm{FBS}^{41}$

HEK cell culture and transfection. HEK $293 \mathrm{~T}$ cells (ATCC, American Type Culture Collection, CRL-3216) were transfected with $\beta 2$ - or $\beta 3$-AR mammalian expression plasmids using Lipofectamine 2000 (Thermo Fisher Scientific), following the manufacturer's instructions. The expression plasmid coding for the human $\beta 2$-AR (vector backbone: pcDNA 3.1) was kindly provided by Dr. Vsevolod Gurevich (Vanderbilt Univesity). The expression construct encoding the mouse $\beta 3$ AR (vector backbone: pCMV6) was purchased from OriGene Technologies Inc. Six hour after transfections, $1 \times 10^{5}$ cells were plated in collagen-coated 24-well plates. Cells were allowed to grow for $48 \mathrm{~h}$ and then used for experiments.

Body composition analysis. The lean/fat mass composition of mutant and control mice was measured using the 3-in-1 Echo MRI Analyzer (Echo Medical System).

Propranolol treatment. Mice (4-week-old males) were placed on a HFD for 8 weeks in the presence of propranolol. Propranolol was added to the drinking water at a concentration of $0.5 \mathrm{~g} / \mathrm{kg}^{58,59}$. During this period, body weights were measured once per week. At the end of HFD feeding period, the mice were subjected to various metabolic tests.

Studies at thermoneutrality. Mice (4-week-old males) were kept at $30^{\circ} \mathrm{C}$ and then maintained on a HFD for 8 weeks. Body weights were measured weekly, and metabolic tests were performed at the end of the HFD feeding period.

Cold exposure of mice. Mice (4-week-old males) were maintained on a HFD for 12 weeks. The mice were then acclimatized to $4{ }^{\circ} \mathrm{C}$ over a period of one week by reducing the environmental temperature incrementally by $2^{\circ} \mathrm{C} /$ day. After this acclimatization period, mice were kept at $4^{\circ} \mathrm{C}$ for one week.

Radioligand binding assay with cultured cells. Differentiated 3T3-F442A or HEK $293 \mathrm{~T}$ cells were incubated with DMEM-Hepes $(50 \mathrm{mM})$ for $30 \mathrm{~min}$ at $37^{\circ} \mathrm{C}$ in a $10 \%$ or $5 \% \mathrm{CO}_{2}$ incubator, respectively. In a subset of experiments, 3T3-F442A cells were treated with barbadin $(100 \mu \mathrm{M} \text { for } 30 \mathrm{~min})^{37}$, filipin $(1 \mu \mathrm{g} / \mathrm{ml} \text { for } 60 \mathrm{~min})^{60}$, or dynasore $(80 \mu \mathrm{M} \text { for } 60 \mathrm{~min})^{61}$. To stimulate $\beta$-AR internalization, cells were incubated with $1 \mu \mathrm{M}$ CL316243 ( $\beta 3$-AR agonist) or $10 \mu \mathrm{M}$ isoproterenol (non-selective $\beta$ AR agonist) for $30 \mathrm{~min}$ at $37^{\circ} \mathrm{C}$ in the same buffer. When 3T3-F442A cells were exposed to CL316243, $\beta 1$ - and $\beta 2$-ARs were blocked with CGP-20712 $(500 \mathrm{nM})$ and ICI-118551 $(100 \mathrm{nM})$, respectively, to ensure that CL316243 exclusively activated $\beta 3$ ARs. After the $30 \mathrm{~min}$ agonist stimulation period, cells were washed with ice-cold DMEM-Hepes and then incubated with $1 \mathrm{nM}$ of the radioligand $\left[\mathrm{I}^{125}\right] \mathrm{CYP}$ (specific activity: $3.7 \mathrm{MBq}$; PerkinElmer, MA) for $2 \mathrm{~h}$ at $4^{\circ} \mathrm{C}$ in DMEM-Hepes $(50 \mathrm{mM})$ binding buffer (incubation volume: $300 \mu \mathrm{l}$ ). Non-specific binding was determined as binding in the presence of propranolol $(100 \mu \mathrm{M})$, a blocker of all $\beta$-ARs. Subsequently, the cells were quickly washed with PBS and lysed with $0.05 \mathrm{~N} \mathrm{NaOH}$. Radioactivity was counted using a Wizard Gamma Counter (PerkinElmer). The amount of radioactivity was normalized to the amount of protein present in the sample.

Binding assay with iWAT plasma membrane preparations. Subcutaneous fat pads from iWAT were collected from mutant and control mice and homogenized in a buffer containing $250 \mathrm{mM}$ sucrose, $10 \mathrm{mM}$ Tris $\mathrm{HCl}$, and $1 \mathrm{mM}$ EDTA. Plasma membrane preparations were obtained as described ${ }^{62}$. In brief, homogenates were first centrifuged at $960 \times g$ for $2 \mathrm{~min}$ at $4^{\circ} \mathrm{C}$. The supernatant was then centrifuged at $20,000 \times g$ for $20 \mathrm{~min}$ at $4^{\circ} \mathrm{C}$. The resulting pellet was resuspended in homogenization buffer, layered on a sucrose gradient, and centrifuged at $160,000 \times g$ for $60 \mathrm{~min}$. The bottom layer containing the plasma membrane fraction was recentrifuged at $150,000 \times g$ for 60 min. Subsequently, the resulting pellet was dissolved in homogenization buffer. The resulting plasma membrane preparations were then used for radioligand binding studies.

Binding assays were performed as described ${ }^{6}$. In brief, binding buffer consisted of $50 \mathrm{mM}$ HEPES, $4 \mathrm{mM} \mathrm{MgCl}$, and $0.04 \% \mathrm{BSA}$ (total incubation volume: $200 \mu \mathrm{l}$ ). The binding mixture contained $5 \mu \mathrm{g}$ of plasma membrane protein and $1 \mathrm{nM}$ of $\left[\mathrm{I}^{125}\right]$ CYP. To ensure that $\left[\mathrm{I}^{125}\right] \mathrm{CYP}$ selectively labeled $\beta 3$-ARs, CGP-20712 $(500 \mathrm{nM} ; \beta 1$-AR-selective blocker) and ICI-118551 (100 nM; $\beta 2$-AR-selective blocker) were added to the binding mixture. Binding reactions were carried out at $30^{\circ} \mathrm{C}$ for $3 \mathrm{~h}$ and then terminated by rapid filtration over GF/C fiber filters (Brandel), followed by several washes with ice-cold buffer containing $20 \mathrm{mM}$ Tris$\mathrm{HCl}$, (pH 7.4) and $2 \mathrm{mM} \mathrm{MgCl}_{2}$. Non-specific binding was determined as binding in the presence of propranolol $(100 \mu \mathrm{M})$. Radioactivity was counted using a Wizard Gamma Counter (PerkinElmer).

Isolation of mouse mitochondria. Subcutaneous fat pads (iWAT) were collected from control and mutant mice and homogenized on ice using a Teflon glass homogenizer in TES buffer ( $250 \mathrm{mM}$ sucrose, $50 \mathrm{mM}$ Tris-HCl, $\mathrm{pH}$ 7.4, $1 \mathrm{mM}$ EDTA), supplemented with protease inhibitors (Sigma) and $1 \mathrm{mM}$ PMSF. All centrifugation steps were performed for $10 \mathrm{~min}$ at $4^{\circ} \mathrm{C}$. Homogenates were centrifuged at $1000 \times g$, and the infranatants were collected and centrifuged at $1000 \times g$. Pellets were resuspended in TES buffer and re-centrifuged at 1000. The supernatants were then centrifuged at $10,000 \times g$ to pellet down crude mitochondria. Pellets were suspended in resuspension buffer ( $250 \mathrm{mM}$ sucrose, $5 \mathrm{mM}$ Tris-HCl, $\mathrm{pH}$ 7.4, $0.5 \mathrm{mM}$ EDTA), supplemented with protease inhibitors (Sigma) and $1 \mathrm{mM}$ PMSF, and recentrifuged at $8500 \times g$. The final pellets were suspended in $100 \mu \mathrm{l}$ of resuspension buffer and used for experiments.

Measurement of mitochondrial DNA content. Total DNA was extracted from iWAT of HFD adipo-barr2-KO and control mice using a Qiagen DNA extraction kit. One ng of total DNA was used to determine the ratio of mitochondrial cyclooxygenase (CoxII) to nuclear intron of $\beta$-globin by real-time PCR ${ }^{64}$. Primer sequences are shown in Supplementary Table 3.

RNA-seq studies. High throughput sequencing libraries were constructed from total RNA extracted from iWAT of adipo-barr2-KO and control mice maintained on HFD for 8 weeks ( $n=3$-6/group). RNAs with RIN $>8$, as assessed by the Agilent 2100 Bioanalyzer system, were used to prepare transcriptome libraries using the NEBNext Ultra RNA library prep kit (New England Biolabs). High throughput sequencing was performed using a HiSeq 2500 instrument (Illumina) at the NIDDK Genomic Core Facility (NIH, Bethesda, MD). Raw reads were mapped to the mouse (mm9) genome. Differentially expressed genes were identified using EdgeR with a $\log 2$ (fold change) cutoff of \pm 0.58 using the Genomatix Genome Analyzer. Biological pathway and enrichment analysis was performed using Metacore (version 6.32, Thomson Reuters, New York). The RNA sequencing data that support the findings of this study have been submitted to the NCBI Sequence Read Archive under the accession code SRP187976.

Indirect calorimetry and energy expenditure measurements. An Oxymax/ CLAMS monitoring system (Columbus Instruments) was used to measure energy expenditure $\left(\mathrm{O}_{2}\right.$ consumption and $\mathrm{CO}_{2}$ production), food intake, and locomotor activity (measurement of beam breaks) simultaneously in mice housed at $22^{\circ} \mathrm{C}$ or $30^{\circ} \mathrm{C}$. Sampling was performed every $13 \mathrm{~min}$, measuring from 12 chambers. Data were collected for $24 \mathrm{~h}$ after 2 days of adaptation to the chambers ${ }^{65}$. Diet-induced thermogenesis was tested at $22^{\circ} \mathrm{C}$ by monitoring mice fed chow diet for 3 days, followed by a 4-day exposure to HFD. Water and food were provided ad libitum.

Mitochondrial CK activity. CK activity was measured using mitochondria isolated from iWAT samples of cold-exposed mice by employing a commercially available kit, following the manufacturer's instructions (Sigma). Values were normalized to protein concentrations.

Isolation of mature adipocytes. Inguinal fat pads (iWAT) from both $\mathrm{KO}$ and control mice were collected and digested with KRH buffer (2\% FFA-free BSA) containing collagenase 1 via incubation at $37^{\circ} \mathrm{C}$ for $30-45 \mathrm{~min}$. Once the tissue was fully digested, $10 \mathrm{ml}$ of $\mathrm{KRH}$ buffer was added to prevent further collagenase activity. Cells were then filtered through a $250 \mu \mathrm{m}$ cell strainer. After $10 \mathrm{~min}$, the floating top layer containing mature adipocytes was collected. Mature adipocytes were washed twice with KRH buffer containing $5 \mathrm{mM}$ EDTA and then used for lipolysis or cAMP assays.

Tissue and urine norepinephrine (NE) levels. Tissue and urine NE levels were quantified using an ELISA kit (Rocky Mountain Diagnostics). Tissues (iWAT) were homogenized using assay buffer containing $0.01 \mathrm{~N} \mathrm{HCl}, 1 \mathrm{mM}$ EDTA, and $4 \mathrm{mM}$ $\mathrm{Na}_{2} \mathrm{~S}_{2} \mathrm{O}_{5}$. Tissue lysates were centrifuged at $\sim 15,000 \times g$ for 15 min at $4{ }^{\circ} \mathrm{C}$ to remove debris and fat. NE levels were measured in the supernatant by following the manufacturer's instructions.

For urine NE measurements, mice were housed individually in metabolic cages for $24 \mathrm{~h}$. Urine was collected over the $24 \mathrm{~h}$ period in tubes containing $6 \mathrm{~N} \mathrm{HCl}$ and protected from light by wrapping tubes in aluminum foil. Urine NE levels were measured via ELISA, as described in the previous paragraph.

Measurement of tissue noradrenergic turnover. The concentrations of the catecholamines NE and dopamine and their precursors or metabolites 3,4-dihydrophyphenylalanine (DOPA), 3,4-dihydroxyphenylglycol (DHPG), and 3,4 dihydroxyphenylacetic acid (DOPAC) were quantified in mouse iWAT by liquid chromatography with electrochemical detection. Frozen tissue samples were weighed and homogenized in $0.5 \mathrm{ml}$ of $0.4 \mathrm{M}$ perchloric acid containing $0.5 \mathrm{mM}$ EDTA. Homogenates were centrifuged and supernatants collected and stored at $-80^{\circ} \mathrm{C}$ until 
assayed. Concentrations of catecholamines and their precursors or metabolites were determined after extraction from perchloric acid-treated tissue supernatants using alumina adsorption ${ }^{66}$. Since all DOPAC values were below the detection limit, they were not used for the final calculation of noradrenergic turnover.

cAMP assay. Primary mouse mature adipocytes were suspended in KRH buffer containing $100 \mu \mathrm{M}$ IBMX. Cells were aliquoted into $1.5 \mathrm{ml}$ tubes and treated with increasing concentrations of CL316243 ( $\beta 3$-AR-selective agonist), fenoterol ( $\beta 2$ AR-selective agonist), xamoterol ( $\beta 1$-AR-selective agonist), or $100 \mu \mathrm{M}$ of forskolin for $30 \mathrm{~min}$ at $37^{\circ} \mathrm{C}$. Cells were then lysed, and changes in intracellular cAMP levels were determined by using a FRET-based cAMP detection kit (cAMP dynamic 2 kit; Cisbio Bioassays $)^{67}$. Tissue (iWAT) cAMP levels were measured using an ELISA kit (Cayman Chemical). Tissue samples were homogenized as per the manufacturer's protocol. Tissue lysates were centrifuged at $\sim 15,000 \times g$ for $15 \mathrm{~min}$ at $4{ }^{\circ} \mathrm{C}$, and cAMP levels were determined in the supernatant.

Ex vivo lipolysis assay. Mature murine adipocytes were aliquoted into $1.5 \mathrm{ml}$ tubes and treated with CL316243 $(0.1$ and $1 \mu \mathrm{M})$, isoproterenol $(1$ and $10 \mu \mathrm{M})$, or forskolin $(100 \mu \mathrm{M})$ for $2 \mathrm{~h}$ at $37^{\circ} \mathrm{C}$ in a water bath placed on a shaking platform $(125 \mathrm{rpm})$. Subsequently, glycerol levels in the media were determined as a measure of lipolysis. Glycerol concentrations were measured by using a glycerol assay kit (Sigma).

Adipocyte mitochondrial oxygen consumption rate. Adipocyte mitochondrial oxygen consumption rate (OCR) was measured using the Seahorse XF96 analyzer (Seahorse Bioscience Inc.). Preadipocytes were isolated from mouse iWAT and plated at a density of 6000 cells/well. Preadipocytes were differentiated into mature adipocytes by using the differentiation protocol described under "Differentiation of 3T3-F442A Cells". Differentiated adipocytes were maintained in DMEM containing $10 \% \mathrm{FBS}$ for $24 \mathrm{~h}$ and then stimulated with isoproterenol $(10 \mu \mathrm{M})$ or CL316243 $(1 \mu \mathrm{M})$ at $37^{\circ} \mathrm{C}$ to measure increases in mitochondrial OCR.

Collection of human subcutaneous adipose tissue. We complied with all relevant ethical regulations for work with human participants. Subjects were admitted to the Metabolic Clinical Research Unit in the Hatfield Clinical Research Center of the National Institutes of Health (Bethesda, MD) to participate in an NIDDK/ NIAMS institutional review board-approved protocol (ClinicalTrials.gov identifier NCT00428987), after having given informed consent. Insulin-resistant, obese subjects and insulin-sensitive, lean subjects were matched for sex, age, and race (for details, see Table S1). None of the subjects was on any medications. Subcutaneous adipose tissue was obtained from the abdominal region via aspiration with an 18gauge needle under local anesthesia. Fat samples were frozen immediately in liquid nitrogen and then stored at $-80^{\circ} \mathrm{C}$ until further use. The insulin sensitivity (SI) index of each subject was calculated using the MinMod Millennium (6.02) program based on results from a frequently sampled intravenous glucose tolerance test (FSIVGTT) performed after a 12 -h overnight fast ${ }^{68}$. Body fat percentage was measured by dual-energy X-ray absorptiometry (Lunar iDXA, GE Healthcare, Madison, WI). RNA was isolated from human fat samples, and qRT-PCR studies were performed as described above for mouse iWAT gene expression.

H\&E staining experiments. BAT, iWAT, and eWAT were dissected from $\mathrm{KO}$ and control mice and fixed in formalin. H\&E staining experiments were performed using standard techniques. The cell surface area of H\&E-stained adipocytes was calculated using Adiposoft software from Fiji ${ }^{69}$.

Statistics. Data are expressed as means \pm s.e.m. for the indicated number of observations. Prior to performing specific statistical tests, we performed tests for normality and homogeneity of variance. Data were then tested for statistical significance by two-way ANOVA, followed by the indicated post hoc tests, or by using a two-tailed unpaired Student's $t$-test, as appropriate. A p value of less than 0.05 was considered statistically significant. The specific statistical tests that were used are indicated in the figure legends.

Study approval. All animal studies were approved by the NIDDK Institutional Animal Care and Use Committee (NIH, Bethesda, MD).

Reporting summary. Further information on research design is available in the Nature Research Reporting Summary linked to this article.

\section{Data availability}

All data underlying this study are available from the corresponding author upon reasonable request.

Received: 18 May 2018 Accepted: 12 June 2019

Published online: 03 July 2019

\section{References}

1. Gonzalez-Muniesa, P. et al. Obesity. Nat. Rev. Dis. Prim. 3, 17034 (2017)

2. Cypess, A. M. et al. Identification and importance of brown adipose tissue in adult humans. N. Engl. J. Med. 360, 1509-1517 (2009).

3. Lidell, M. E. et al. Evidence for two types of brown adipose tissue in humans. Nat. Med. 19, 631-634 (2013).

4. Rosen, E. D. \& Spiegelman, B. M. What we talk about when we talk about fat Cell 156, 20-44 (2014).

5. van Marken Lichtenbelt, W. D. et al. Cold-activated brown adipose tissue in healthy men. N. Engl. J. Med. 360, 1500-1508 (2009).

6. Virtanen, K. A. et al. Functional brown adipose tissue in healthy adults. $N$. Engl. J. Med. 360, 1518-1525 (2009).

7. Wang, W. \& Seale, P. Control of brown and beige fat development. Nat. Rev Mol. Cell Biol. 17, 691-702 (2016).

8. $\mathrm{Wu}, \mathrm{J}$. et al. Beige adipocytes are a distinct type of thermogenic fat cell in mouse and human. Cell 150, 366-376 (2012).

9. Zhu, Q. et al. Adipocyte-specific deletion of Ip6k1 reduces diet-induced obesity by enhancing AMPK-mediated thermogenesis. J. Clin. Invest 126, 4273-4288 (2016)

10. Shao, M. et al. Zfp423 maintains white adipocyte identity through suppression of the beige cell thermogenic gene program. Cell Metab. 23, 1167-1184 (2016).

11. Cohen, P. \& Spiegelman, B. M. Brown and beige fat: molecular parts of a thermogenic machine. Diabetes 64, 2346-2351 (2015).

12. Cohen, P. et al. Ablation of PRDM16 and beige adipose causes metabolic dysfunction and a subcutaneous to visceral fat switch. Cell 156, 304-316 (2014).

13. Kusminski, C. M., Bickel, P. E. \& Scherer, P. E. Targeting adipose tissue in the treatment of obesity-associated diabetes. Nat. Rev. Drug Disco. 15, 639-660 (2016).

14. Harms, M. \& Seale, P. Brown and beige fat: development, function and therapeutic potential. Nat. Med. 19, 1252-1263 (2013)

15. Kajimura, S., Spiegelman, B. M. \& Seale, P. Brown and Beige Fat: physiological Roles beyond Heat Generation. Cell Metab. 22, 546-559 (2015).

16. Kazak, L. et al. Genetic depletion of adipocyte creatine metabolism inhibits diet-induced thermogenesis and drives obesity. Cell Metab. 26, 660-671 (2017).

17. Kazak, L. et al. A creatine-driven substrate cycle enhances energy expenditure and thermogenesis in beige fat. Cell 163, 643-655 (2015).

18. Emont, M. P., Yu, H. \& Wu, J. Transcriptional control and hormonal response of thermogenic fat. J. Endocrinol. 225, R35-R47 (2015).

19. Amisten, S. et al. An atlas of G-protein coupled receptor expression and function in human subcutaneous adipose tissue. Pharm. Ther. 146, 61-93 (2015).

20. Gnad, T. et al. Adenosine activates brown adipose tissue and recruits beige adipocytes via A2A receptors. Nature 516, 395-399 (2014).

21. Pierce, K. L., Premont, R. T. \& Lefkowitz, R. J. Seven-transmembrane receptors. Nat. Rev. Mol. Cell Biol. 3, 639-650 (2002).

22. Rajagopal, S., Rajagopal, K. \& Lefkowitz, R. J. Teaching old receptors new tricks: biasing seven-transmembrane receptors. Nat. Rev. Drug Disco. 9, 373-386 (2010).

23. Gurevich, V. V. \& Gurevich, E. V. Overview of different mechanisms of arrestin-mediated signaling. Curr. Protoc. Pharm. 67, 11-19 (2014). Unit 210

24. Zhao, J. \& Pei, G. Arrestins in metabolic regulation. Prog. Mol. Biol. Transl. Sci. 118, 413-427 (2013).

25. Oh, D. Y. \& Olefsky, J. M. G protein-coupled receptors as targets for antidiabetic therapeutics. Nat. Rev. Drug Disco. 15, 161-172 (2016).

26. Urs, N. M. et al. Distinct cortical and striatal actions of a beta-arrestin-biased dopamine D2 receptor ligand reveal unique antipsychotic-like properties. Proc. Natl Acad. Sci. USA 113, E8178-e8186 (2016)

27. Eguchi, J. et al. Transcriptional control of adipose lipid handling by IRF4. Cell Metab. 13, 249-259 (2011).

28. Himms-Hagen, J. et al. Effect of CL-316,243, a thermogenic beta 3-agonist, on energy balance and brown and white adipose tissues in rats. Am. J. Physiol. 266, R1371-R1382 (1994)

29. Yoshida, T., Sakane, N., Wakabayashi, Y., Umekawa, T. \& Kondo, M. Antiobesity and anti-diabetic effects of CL 316,243, a highly specific beta 3adrenoceptor agonist, in yellow KK mice. Life Sci. 54, 491-498 (1994).

30. Collins, S. \& Surwit, R. S. The beta-adrenergic receptors and the control of adipose tissue metabolism and thermogenesis. Recent Prog. Horm. Res. 56, 309-328 (2001)

31. Breit, A., Lagace, M. \& Bouvier, M. Hetero-oligomerization between beta2and beta3-adrenergic receptors generates a beta-adrenergic signaling unit with distinct functional properties. J. Biol. Chem. 279, 28756-28765 (2004).

32. Cao, W. et al. Direct binding of activated c-Src to the beta 3-adrenergic receptor is required for MAP kinase activation. J. Biol. Chem. 275, 38131-38134 (2000). 
33. Nantel, F. et al. The human beta 3-adrenergic receptor is resistant to short term agonist-promoted desensitization. Mol. Pharm. 43, 548-555 (1993).

34. Liggett, S. B., Freedman, N. J., Schwinn, D. A. \& Lefkowitz, R. J. Structural basis for receptor subtype-specific regulation revealed by a chimeric beta $3 /$ beta 2-adrenergic receptor. Proc. Natl Acad. Sci. USA 90, 3665-3669 (1993).

35. Feve, B., Elhadri, K., Quignard-Boulange, A. \& Pairault, J. Transcriptional down-regulation by insulin of the beta 3 -adrenergic receptor expression in 3T3-F442A adipocytes: a mechanism for repressing the cAMP signaling pathway. Proc. Natl Acad. Sci. USA 91, 5677-5681 (1994).

36. Hertel, C. \& Perkins, J. P. Receptor-specific mechanisms of desensitization of beta-adrenergic receptor function. Mol. Cell. Endocrinol. 37, 245-256 (1984).

37. Beautrait, A. et al. A new inhibitor of the beta-arrestin/AP2 endocytic complex reveals interplay between GPCR internalization and signalling. Nat. Commun. 8, 15054 (2017).

38. Macia, E. et al. Dynasore, a cell-permeable inhibitor of dynamin. Dev. Cell 10, 839-850 (2006).

39. Ostrom, R. S. \& Insel, P. A. The evolving role of lipid rafts and caveolae in G protein-coupled receptor signaling: implications for molecular pharmacology. Br. J. Pharmacol. 143, 235-245 (2004).

40. Pacak, K. et al. Hypercortisolemia inhibits yohimbine-induced release of norepinephrine in the posterolateral hypothalamus of conscious rats. Endocrinology 131, 1369-1376 (1992).

41. Bugge, A., Dib, L. \& Collins, S. Measuring respiratory activity of adipocytes and adipose tissues in real time. Methods Enzym. 538, 233-247 (2014).

42. Bertholet, A. M. et al. Mitochondrial patch clamp of beige adipocytes reveals UCP1-positive and UCP1-negative cells both exhibiting futile creatine cycling. Cell Metab. 25, 811-822 e814 (2017).

43. Cui, X. et al. Thermoneutrality decreases thermogenic program and promotes adiposity in high-fat diet-fed mice. Physiol. Rep. 4, e12799 (2016).

44. Cannon, B. \& Nedergaard, J. Brown adipose tissue: function and physiological significance. Physiol. Rev. 84, 277-359 (2004).

45. Chen, C. H., Paing, M. M. \& Trejo, J. Termination of protease-activated receptor-1 signaling by beta-arrestins is independent of receptor phosphorylation. J. Biol. Chem. 279, 10020-10031 (2004).

46. Min, L., Galet, C. \& Ascoli, M. The association of arrestin-3 with the human lutropin/choriogonadotropin receptor depends mostly on receptor activation rather than on receptor phosphorylation. J. Biol. Chem. 277, 702-710 (2002).

47. Jala, V. R., Shao, W. H. \& Haribabu, B. Phosphorylation-independent betaarrestin translocation and internalization of leukotriene B4 receptors. J. Biol. Chem. 280, 4880-4887 (2005).

48. Rankovic, Z., Brust, T. F. \& Bohn, L. M. Biased agonism: an emerging paradigm in GPCR drug discovery. Bioorg. Med. Chem. Lett. 26, 241-250 (2016).

49. Wisler, J. W., Xiao, K., Thomsen, A. R. \& Lefkowitz, R. J. Recent developments in biased agonism. Curr. Opin. Cell Biol. 27, 18-24 (2014).

50. Kenakin, T. \& Christopoulos, A. Signalling bias in new drug discovery: detection, quantification and therapeutic impact. Nat. Rev. Drug Disco. 12, 205-216 (2013).

51. Shonberg, J. et al. Biased agonism at $\mathrm{G}$ protein-coupled receptors: the promise and the challenges-a medicinal chemistry perspective. Med Res Rev. 34 $1286-1330$ (2014).

52. Luttrell, L. M., Maudsley, S. \& Bohn, L. M. Fulfilling the promise of "Biased" G protein-coupled receptor agonism. Mol. Pharm. 88, 579-588 (2015).

53. Revelli, J. P., Muzzin, P., Paoloni, A., Moinat, M. \& Giacobino, J. P. Expression of the beta 3-adrenergic receptor in human white adipose tissue. J. Mol. Endocrinol. 10, 193-197 (1993).

54. Krief, S. et al. Tissue distribution of beta 3-adrenergic receptor mRNA in man. J. Clin. Invest 91, 344-349 (1993).

55. Cypess, A. M. et al. Activation of human brown adipose tissue by a beta3adrenergic receptor agonist. Cell Metab. 21, 33-38 (2015).

56. de Souza, C. J. \& Burkey, B. F. Beta 3-adrenoceptor agonists as anti-diabetic and anti-obesity drugs in humans. Curr. Pharm. Des. 7, 1433-1449 (2001).

57. Mund, R. A. \& Frishman, W. H. Brown adipose tissue thermogenesis: beta3adrenoreceptors as a potential target for the treatment of obesity in humans. Cardiol. Rev. 21, 265-269 (2013).

58. Baek, K. et al. Propranolol, a beta-adrenergic antagonist, attenuates the decrease in trabecular bone mass in high calorie diet fed growing mice. $B M B$ Rep. 47, 506-511 (2014).

59. Baek, K., Park, H. J., Hwang, H. R. \& Baek, J. H. Propranolol attenuates calorie restriction- and high calorie diet-induced bone marrow adiposity. BMB Rep. 47, 587-592 (2014)

60. Gupte, T. M., Malik, R. U., Sommese, R. F., Ritt, M. \& Sivaramakrishnan, S. Priming GPCR signaling through the synergistic effect of two G proteins. Proc. Natl Acad. Sci. USA 114, 3756-3761 (2017).

61. Calebiro, D. et al. Persistent cAMP-signals triggered by internalized Gprotein-coupled receptors. PLoS Biol. 7, e1000172 (2009).
62. Lewis, D. S., Cellucci, M. D., Masoro, E. J. \& Yu, B. P. An improved method for the isolation of adipocyte plasma membranes. Anal. Biochem. 96, 236-245 (1979).

63. Dunigan, C. D., Curran, P. K. \& Fishman, P. H. Detection of beta-adrenergic receptors by radioligand binding. Methods Mol. Biol. 126, 329-343 (2000).

64. Liu, H. Y. et al. Prolonged exposure to insulin suppresses mitochondrial production in primary hepatocytes. J. Biol. Chem. 284, 14087-14095 (2009).

65. $\mathrm{Yu}, \mathrm{S}$. et al. Paternal versus maternal transmission of a stimulatory G-protein alpha subunit knockout produces opposite effects on energy metabolism. J. Clin. Invest 105, 615-623 (2000).

66. Eisenhofer, G. et al. Simultaneous liquid-chromatographic determination of 3,4-dihydroxyphenylglycol, catecholamines, and 3,4-dihydroxyphenylalanine in plasma, and their responses to inhibition of monoamine oxidase. Clin. Chem. 32, 2030-2033 (1986).

67. Nakajima, K. \& Wess, J. Design and functional characterization of a novel, arrestin-biased designer G protein-coupled receptor. Mol. Pharm. 82, 575-582 (2012).

68. Saad, M. F. et al. Method of insulin administration has no effect on insulin sensitivity estimates from the insulin-modified minimal model protocol. Diabetes 46, 2044-2048 (1997).

69. Galarraga, M. et al. Adiposoft: automated software for the analysis of white adipose tissue cellularity in histological sections. J. Lipid Res. 53, 2791-2796 (2012).

\section{Acknowledgements}

This research was funded by the Intramural Research Program of the National Institute of Diabetes and Digestive and Kidney Diseases (NIDDK, NIH), the National Heart, Lung, and Blood Institute (NHLBI, NIH), and the National Institute of Child Health and Human Development (NICHD, NIH). The floxed Prdm16 mice were kindly provided by Drs. Paul Cohen and Bruce Spiegelman (Harvard Medical School, Boston, MA). We thank Dr. Vsevolod V. Gurevich (Vanderbilt University) for helpful discussions throughout the course of this study. Drs. Harold Smith and Chithra Keembiyehetty at the NIDDK Genomic Core provided expert support with the RNA-seq work. We also thank Yinyan Ma and Naili Liu (Mouse Metabolism Core, NIDDK) for carrying out several metabolite and hormone measurements.

\section{Author contributions}

S.P.P., T.F., and J.W. designed and conceived the experiments. S.P.P., S.J., W.T., Y.C., L. Z., W.S., and S.J. performed and analyzed the experiments. J.L. and T.F. supervised and interpreted the Seahorse experiments. T.H. and K.P. carried out and interpreted the noradrenergic turnover studies. O.G. provided guidance with several of the metabolic studies. B.S.A. and M.C.S. collected and provided the human fat samples. M.G.C. generated the floxed barr 2 mice and provided helpful advice throughout the study. S.P.P. and J.W. wrote the manuscript.

\section{Additional information}

Supplementary Information accompanies this paper at https://doi.org/10.1038/s41467 019-11003-4.

Competing interests: The authors declare no competing interests.

Reprints and permission information is available online at http://npg.nature.com/ reprintsandpermissions/

Peer review information: Nature Communications thanks the anonymous reviewer(s) for their contribution to the peer review of this work.

Publisher's note: Springer Nature remains neutral with regard to jurisdictional claims in published maps and institutional affiliations.

Open Access This article is licensed under a Creative Commons Attribution 4.0 International License, which permits use, sharing, adaptation, distribution and reproduction in any medium or format, as long as you give appropriate credit to the original author(s) and the source, provide a link to the Creative Commons license, and indicate if changes were made. The images or other third party material in this article are included in the article's Creative Commons license, unless indicated otherwise in a credit line to the material. If material is not included in the article's Creative Commons license and your intended use is not permitted by statutory regulation or exceeds the permitted use, you will need to obtain permission directly from the copyright holder. To view a copy of this license, visit http://creativecommons.org/ licenses/by/4.0/

This is a U.S. Government work and not under copyright protection in the US; foreign copyright protection may apply 2019 